\title{
What controls biological production in coastal upwelling systems? Insights from a comparative modeling study
}

\author{
Z. Lachkar and N. Gruber \\ Environmental Physics, Institute of Biogeochemistry and Pollutant Dynamics, ETH Zurich, Universitätstrasse 16, \\ 8092 Zurich, Switzerland
}

Received: 29 May 2011 - Published in Biogeosciences Discuss.: 14 June 2011

Revised: 1 October 2011 - Accepted: 9 October 2011 - Published: 21 October 2011

\begin{abstract}
The magnitude of net primary production (NPP) in Eastern Boundary Upwelling Systems (EBUS) is traditionally viewed as directly reflecting the wind-driven upwelling intensity. Yet, different EBUS show different sensitivities of NPP to upwelling-favorable winds (Carr and Kearns, 2003). Here, using a comparative modeling study of the California Current System (California CS) and Canary Current System (Canary CS), we show how physical and environmental factors, such as light, temperature and cross-shore circulation modulate the response of NPP to upwelling strength. To this end, we made a series of eddyresolving simulations of the two upwelling systems using the Regional Oceanic Modeling System (ROMS), coupled to a nitrogen-based Nutrient-Phytoplankton-ZooplanktonDetritus (NPZD) ecosystem model. Using identical ecologi$\mathrm{cal} / \mathrm{biogeochemical} \mathrm{parameters,} \mathrm{our} \mathrm{coupled} \mathrm{model} \mathrm{simulates}$ a level of NPP in the California CS that is $50 \%$ smaller than that in the Canary CS, in agreement with observationally based estimates. We find this much lower NPP in the California CS despite phytoplankton in this system having nearly $20 \%$ higher nutrient concentrations available to fuel their growth. This conundrum can be explained by: (1) phytoplankton having a faster nutrient-replete growth in the Canary CS relative to the California CS; a consequence of more favorable light and temperature conditions in the Canary CS, and (2) the longer nearshore water residence times in the Canary CS, which permit a larger buildup of biomass in the upwelling zone, thereby enhancing NPP. The longer residence times in the Canary CS appear to be a result of the wider continental shelves and the lower mesoscale activity characterizing this upwelling system. This results in a weaker offshore export of nutrients and organic matter, thereby increasing local nutrient recycling and reducing the spatial decou-
\end{abstract}

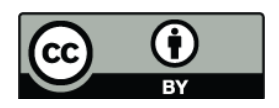

Correspondence to: Z. Lachkar (zouhair.lachkar@env.ethz.ch) pling between new and export production in the Canary CS. Our results suggest that climate change-induced perturbations such as upwelling favorable wind intensification might lead to contrasting biological responses in the California CS and the Canary CS, with major implications for the biogeochemical cycles and fisheries in these two ecosystems.

\section{Introduction}

Eastern boundary upwelling systems (EBUS) are among the most productive marine ecosystems in the world and are well known for supporting some of the world's major fisheries (Pauly and Christensen, 1995; Bakun, 1990; Carr, 2001; Carr and Kearns, 2003; FAO, 2009). Although they represent less than $1 \%$ of the world ocean by area, EBUS account for around $11 \%$ of global new production (Chavez and Toggweiler, 1995) and up to $20 \%$ of the global fish catch (Pauly and Christensen, 1995). This high production supports large downward export of organic carbon (Muller-Karger et al., 2005), in addition to a significant fraction which is exported laterally into the open ocean (e.g., Aristegui et al., 2004). Thus, determining what controls production within EBUS is not only essential to understand the functioning of these ecosystems, but is also relevant for the assessment of the global marine carbon cycle.

The high production in EBUS is driven, to the first order, by the upwelling of nutrient-rich water associated with the equatorward winds along the eastern boundaries of the Atlantic and Pacific (Allen, 1973; Brink, 1983). Yet, individual upwelling systems show substantial differences in net primary production (NPP) for reasons that remain neither well understood nor well quantified (Carr, 2001; Thomas et al., 2001; Carr and Kearns, 2003; Lachkar and Gruber, 2011). Here, we examine the production drivers in EBUS with a particular focus on the mechanisms that control the sensitivity of biological production to upwelling intensity.

Published by Copernicus Publications on behalf of the European Geosciences Union. 
To this end, we contrast two of the four major EBUS, namely the California Current System (California CS) and the Canary Current System (Canary CS). Our goal is to identify the major limitations of biological production in these systems and to improve our understanding of how different environmental and physical conditions can alter the sensitivity of production to the wind forcing in EBUS. The comparison of the two systems provides a framework for developing a more comprehensive view of the factors that influence the sensitivity of biological production to wind forcing and for a better understanding of the underlying dynamics of EBUS ecosystems in general (Lachkar and Gruber, 2011). This can also be useful for predicting the response of EBUS to potential wind changes induced by climate change (Bakun, 1990; Shannon et al., 1992; Mendelssohn, 2002; McGregor et al., 2007).

Over the last decade, several comparative studies of EBUS have been conducted using satellite observations to identify commonalities and differences in the production regimes characterizing these systems (Thomas et al., 2001; Carr, 2001; Carr and Kearns, 2003; Demarcq, 2009; Lachkar and Gruber, 2011). For instance, Carr and Kearns (2003) examined some potential governing factors for biological production that they separated into local forcing and large-scale circulation related factors. They found the Atlantic EBUS to support larger biomass than the Pacific EBUS despite a lower nutrient supply. These authors hypothesized this might be due to differences in iron limitation, community structure or biomass retention between the two basins. Demarcq (2009) showed that recent observed changes in surface chlorophyll and production in EBUS are only moderately correlated with changes in wind, suggesting a contrasting sensitivity of the production to the upwelling changes in the different EBUS. Using a Self-Organizing Map (SOM) analysis of recent satellite data, Lachkar and Gruber (2011) found that the sensitivity of biological production to upwelling-favorable wind is fundamentally different between the Atlantic and the Pacific EBUS, and proposed parameters such as the width of continental shelf and the level of eddy activity as factors potentially explaining these contrasts. A modeling approach is needed to test these hypotheses and gain a mechanistic understanding of the underlying dynamics controlling production in EBUS. Yet, no comparative modeling study of production regimes in EBUS has been undertaken yet, in part due to the large efforts required to set up, run, and evaluate regional models consistently across different EBUS. We show here how by using the same model with identical settings for two different EBUS, one can gain insight into the sensitivity of biological production to the local physical and environmental conditions. Based on a simple NPZD-type ecosystem model, our study highlights the importance of physics as a primary driver for the contrasting production regimes observed in the two upwelling systems. Finally, by modeling the California CS and the Canary CS at an eddy-resolving resolution, we aim at properly capturing the role of the mesoscale variabil- ity. Previous studies have, indeed, shown that eddies are particularly important for the dynamics of EBUS (Rossi et al., 2008; Marchesiello and Estrade, 2009; Gruber et al., 2011; Lachkar and Gruber, 2011).

\section{Methods}

\subsection{Model details}

\subsubsection{The circulation model}

Our circulation model is based on the UCLA version of the Regional Oceanic Modeling System (ROMS) (Shchepetkin and McWilliams, 2005). ROMS solves the primitive equations with a free sea surface, horizontal curvilinear coordinates, and a generalized terrain-following vertical coordinate (Marchesiello et al., 2003; Shchepetkin and McWilliams, 2005). The time stepping is a leapfrog/AdamsMoulton, predictor-corrector scheme, which is third-order accurate in time (Marchesiello et al., 2003). The openboundary conditions are a combination of outward radiation and flow-adaptive nudging toward prescribed external conditions (Marchesiello et al., 2001). Advection is represented using a third order and upstream biased operator, designed to reduce dispersive errors and the excessive dissipation rates needed to maintain smoothness (Shchepetkin and McWilliams, 1998). Vertical diffusivity in the interior and planetary boundary layers is given by the nonlocal K-Profile Parameterization (KPP) scheme (Large et al., 1994).

The bathymetry is calculated using the $2^{\prime}$ bathymetry file ETOPO2 from the National Geophysical Data Center (Smith and Sandwell, 1997). Depths shallower than $50 \mathrm{~m}$ are reset to $50 \mathrm{~m}$. After interpolation and truncation, the topography is smoothed using a selective Shapiro filter for excessive topographic slope parameter values (Beckmann and Haidvogel, 1993) to avoid large pressure gradient errors.

\subsubsection{The Ecosystem/Biogeochemistry model}

The ecological-biogeochemical model is a nitrogen based NPZD model described in detail by Gruber et al. (2006). It consists of a system of seven coupled partial differential equations that govern the time and space distribution of the following non-conservative scalars: nitrate $\left(\mathrm{NO}_{3}^{-}\right)$subsequently denoted as $N_{\mathrm{n}}$ to reflect "new" nitrogen, ammonium $\left(\mathrm{NH}_{4}^{+}\right)$, denoted as $N_{\mathrm{r}}$ to reflect regenerated nitrogen, phytoplankton $(P)$, zooplankton $(Z)$, small $\left(D_{\mathrm{S}}\right)$ and large $\left(D_{\mathrm{L}}\right)$ detritus, and a dynamic phytoplankton chlorophyll-to-carbon ratio $(\theta)$.

The model has two pools of detritus; a large one that sinks fast, and a small one that sinks slowly. The small detrital pool coagulates with phytoplankton, thereby forming large, fast sinking detritus. Sinking is modeled explicitly, thereby permitting all state variables to be advected laterally even in the aphotic zone. 
The biological source minus sink flux for phytoplankton, $J(P)$, is given by:

$$
\begin{aligned}
J(P) & =\mu_{P}\left(T, I, N_{\mathrm{n}}, N_{\mathrm{r}}\right) \cdot P-\Phi^{\mathrm{graz}}(P, Z) \cdot P \\
& -\Phi^{\mathrm{mort}} \cdot P-\Phi^{\mathrm{coag}}\left(P, D_{S}\right) \cdot P
\end{aligned}
$$

The first term on the right-hand side of Eq. (1) is primary production with $\mu_{P}\left(T, I, N_{\mathrm{n}}, N_{\mathrm{r}}\right)$ being the growth rate of phytoplankton. The other three terms represent, grazing, mortality and coagulation, respectively. Phytoplankton growth is limited in our model by the amount of photosynthetically available radiation (PAR), $I$, the concentrations of nitrate, $N_{\mathrm{n}}$, and ammonium, $N_{\mathrm{r}}$ and temperature, $T$ in the following manner:

$\mu_{P}\left(T, I, N_{\mathrm{n}}, N_{\mathrm{r}}\right)=\mu_{P}^{\max }(T, I) \cdot \gamma\left(N_{\mathrm{n}}, N_{\mathrm{r}}\right)$

where $\mu_{P}^{\max }(T, I)$ is the temperature-dependent, light-limited growth rate under nutrient replete conditions and $\gamma\left(N_{\mathrm{n}}, N_{\mathrm{r}}\right)$ is a non-dimensional nutrient limitation factor. The temperature-dependent, light-limited growth rate is given by:

$\mu_{P}^{\max }(T, I)=\frac{\mu_{P}^{T}(T) \cdot \alpha_{P} \cdot I \cdot \theta}{\sqrt{\left(\mu_{P}^{T}(T)\right)^{2}+\left(\alpha_{P} \cdot I \cdot \theta\right)^{2}}}$

where $\alpha_{P}$ is the initial slope in the growth versus light relationship and $\theta$ the dynamic phytoplankton chlorophyll-tocarbon ratio. The temperature-dependent growth rate $\mu_{P}^{T}(T)$ is parameterized using the relationship of Eppley (1972):

$\mu_{P}^{T}(T)=\ln 2 \cdot 0.851 \cdot(1.066)^{T}$

The nutrient limitation factor $\gamma\left(N_{\mathrm{n}}, N_{\mathrm{r}}\right) \leq 1$, is parameterized using a Michaelis-Menten equation, taking into account that ammonium is taken up preferentially over nitrate, and that its presence inhibits the uptake of nitrate by phytoplankton (Wroblewski, 1977). We use an additive function weighted toward ammonium:

$$
\begin{aligned}
\gamma\left(N_{\mathrm{n}}, N_{\mathrm{r}}\right) & =\gamma\left(N_{\mathrm{n}}\right)+\gamma\left(N_{\mathrm{r}}\right) \\
& =\frac{N_{\mathrm{n}}}{K_{N_{\mathrm{n}}}+N_{\mathrm{n}}} \frac{K_{N_{\mathrm{r}}}}{K_{N_{\mathrm{r}}}+N_{\mathrm{r}}}+\frac{N_{\mathrm{r}}}{K_{N_{\mathrm{r}}}+N_{\mathrm{r}}}
\end{aligned}
$$

where $K_{N_{\mathrm{n}}}$ and $K_{N_{\mathrm{r}}}$ are the half-saturation constants for phytoplankton uptake of nitrate and ammonium, respectively. All model parameters are set identical for both California CS and Canary CS configurations and are those described in detail in Gruber et al. (2006).

\subsection{Model setup}

For the purpose of our comparative study, we developed two ROMS configurations for the California CS and the Canary CS. In the California CS the domain extends in latitude from the middle of Baja California $\left(28^{\circ} \mathrm{N}\right)$ to the Canadian bor$\operatorname{der}\left(48^{\circ} \mathrm{N}\right)$. This is about $2000 \mathrm{~km}$ alongshore and $1000 \mathrm{~km}$ offshore, and it encompasses the California CS and its most energetic eddy region. This is the same setup used by Gruber et al. (2011). In the Canary CS the domain extends in latitude from $10^{\circ} \mathrm{N}$ (latitude of the North Equatorial Current) to $43^{\circ} \mathrm{N}$ (north-west Iberia). This is about $3200 \mathrm{~km}$ alongshore and 1500 to $2500 \mathrm{~km}$ offshore, and it encompasses the entire Canary CS and its different subsystems (Aristegui et al., 2009).

The California CS has a curvilinear grid which follows the shape of the US West Coast. The grid for the Canary CS is an isotropic Mercator grid $\left(1 / 20^{\circ} \times 1 / 20^{\circ} \cos\right.$ (latitude)). Both have an average grid spacing around $5 \mathrm{~km}$, i.e., 4 to 12 times smaller than the Rossby deformation radius which varies between 20 and $60 \mathrm{~km}$ in these regions (Chelton et al., 1998). This allows an explicit resolution of most of the mesoscale eddy spectrum (Chassignet and Verron, 2006). The vertical grid has 32 levels with surface refinement. The stretching parameters for the vertical grid allow for a reasonable representation of the surface boundary layer and the euphotic zone everywhere in the domain. On average, about eight levels are within the euphotic zone, defined here as the $1 \%$ light level. This corresponds to an euphotic depth varying between $50 \mathrm{~m}$ nearshore and $80 \mathrm{~m}$ around $300 \mathrm{~km}$ offshore.

Initial and boundary conditions for the temperature, salinity and nitrate fields were taken from the World Ocean Atlas 2005. The model was started from rest, then spun up for 10 years with a climatological monthly forcing. Wind stress is taken from the QuikSCAT-based Scatterometer Climatology of Ocean Winds (SCOW) (Risien and Chelton, 2008). The surface heat and freshwater fluxes were derived from the Comprehensive Ocean-Atmosphere Data Set (COADS) (da Silva et al., 1994) and applied with a surface temperature and salinity restoring following the formulation of Barnier et al. (1995). In order to remove the model internal chaotic interannual variability, we generally show and discuss 5-year averages from model years 6 to 10 .

We quantitatively compare the simulations from the two systems as follows: data are averaged for both systems, extending from the coastline to $300 \mathrm{~km}$ offshore and over $1^{\circ}$ bins in meridional direction from $30^{\circ} \mathrm{N}$ to $46^{\circ} \mathrm{N}$ for the California CS, and from $12^{\circ} \mathrm{N}$ to $28^{\circ} \mathrm{N}$ for the Canary CS. These boundaries were chosen to include the most productive regions of these upwelling systems (Fig. 4). Thus, the less productive northern parts of the Canary CS are not included in our analyses here.

\subsection{Model evaluation}

Except for two ecological parameters (the light response parameter $\alpha_{P}$ and phytoplankton mortality $\eta_{\text {mort }}$ ) our California CS setup is identical to that used by Gruber et al. (2011). These newer setups differ, however, from that described by Gruber et al. (2006) in two major ways. First, the newer models are run at $5 \mathrm{~km}$ resolution throughout the domain, while the previous one had a $15 \mathrm{~km}$ resolution over the entire domain, and employed a $5 \mathrm{~km}$ child grid for the central California CS. Second, the circulation model is based 
on a newer numerical core optimized for computations on distributed systems (A. Shchepetkin, personal communication, 2008). Additional modifications include an improved implementation of the KPP scheme, a stiffer scheme for the vertical sigma coordinate system and improved numerics for tracer transport. These changes and the new setup for the $\mathrm{Ca}-$ nary CS require a re-evaluation of the model's performance on the basis of primarily satellite chlorophyll and sea-surface temperature (SST), augmented with a monthly climatology of mixed layer depth based on the Argo float observations. We also evaluate the model's performance with regard to different estimates of NPP.

Simulated annual mean surface chlorophyll-a concentrations compare generally well to SeaWiFS in both the California CS and the Canary CS, although there is an important underestimation of nearshore concentrations (Fig. 1). The model-data discrepancies in the coastal zone may partially be due to a systematic bias in the SeaWiFS data towards higher concentrations in the coastal waters. Indeed, ocean color remote sensing tends to overestimate chlorophyll generally in continental shelf and coastal regions because of increased concentrations of colored optical constituents in the water that vary independently of phytoplankton chlorophyll pigment and absorbing aerosols that tend to be concentrated near the coast (Schollaert et al., 2003; Hyde et al., 2007). This is also consistent with previous results from Gruber et al. (2006) who found similar discrepancies by comparing SeaWiFS chlorophyll with those measured in situ by the CalCOFI program in this region.

The simulated annual mean SST represents well the observed pattern in both the California CS and Canary CS (Fig. 2). In particular, the model successfully captures the offshore extent of the cold upwelling region in both systems. However, as found by Gruber et al. (2006), absolute values of modeled SST exhibit a cold bias of about $1{ }^{\circ} \mathrm{C}$ relative to AVHRR satellite data in most of the California CS as well as in the northern Canary CS. Some of the differences between the model and the data likely reflect true changes over time, since our model was forced with heat fluxes from the COADS climatology, which was derived from observations collected between 1950 to 1989, whereas the AVHRR climatology was put together on the basis of the years 19972005 only. Therefore, the long-term surface ocean warming observed over the last couple of decades will likely lead to higher SST in AVHRR data in comparison with COADS. In the nearshore areas, overestimated wind stress and uncertainties associated with the wind stress profile in the QuikSCAT data is probably further enhancing the cold bias (Capet et al., 2004).

A more quantitative evaluation of the model simulations is depicted in the Taylor (2001) diagrams shown in Fig. 3. A Taylor diagram is an $r-\theta$ polar plot that provides a quick quantitative synthesis of three statistics. First, the modeled field's standard deviation relative to the standard deviation of the observations is represented by the radius $r$ (distance on the plot between the model and the origin point). Second, the angle $\theta$ between the model point and the $\mathrm{X}$-axis indicates the correlation coefficient between the model and the observations. Finally, the distance from the reference point to a given modeled field represents that field's central pattern root mean square (RMS), also known as the pattern error. If a model were perfect, it would lie along the $\mathrm{X}$-axis, right on top of the (observation) reference point.

For both the California CS and the Canary CS, we find relatively high correlations between simulated and satellitebased annual mean surface chlorophyll ranging between 0.68 for the nearshore area of the California CS up to around 0.9 for the Canary CS when estimated over the entire domain (Fig. 3a). The standard deviations of simulated chlorophyll patterns are, however, $30 \%$ to $50 \%$ lower than in SeaWiFS. This is essentially due to the model underestimating SeaWiFS's high values in the immediate nearshore as we mentioned before. The simulated surface temperatures show high agreement with SST observations from AVHRR (Fig. 3a). In particular, the correlations between modeled and observed patterns are particularly high ranging between 0.95 and 0.99 . Finally, the correlation between the simulated mixed layer depth and the Argo-based climatology of de Boyer Montégut et al. (2004) is around 0.7 in the California CS and 0.85 in the Canary CS (Fig. 3a). As nearshore MLD observations are associated with relatively large uncertainties (few Argo floats in the coastal areas), only the patterns related to the entire domain are represented in the Taylor diagrams. In both systems, the modeled mixed layer depths have substantially larger standard deviations relative to observations. This is likely due to the much coarser resolution of the data $\left(2^{\circ}\right)$ in comparison to our model's fine resolution of $\sim 5 \mathrm{~km}$.

The model simulates the seasonal cycle of chlorophyll less successfully than the annual mean pattern (Fig. 3b). In both the California CS and the Canary CS, the correlations of the seasonal anomalies, i.e. of the monthly means minus the annual means, range between 0.3 and 0.45 . This distinct difference between the annual mean and the seasonal component is not reflected in the SST, which shows generally a very good agreement with observations with a correlation around 0.95 and a model variance very close to the observed one. For the mixed layer depth, the correlations of the seasonal anomalies with observations are 0.75 and 0.82 for the Canary CS and the California CS, respectively. In both systems, the model variance is substantially larger than in observations. Again, this is likely due to the coarse resolution of the mixed layer climatology.

In both upwelling systems, simulated NPP matches the observed spatial pattern, but underestimates in-situ and satellite data-based estimates (see Tables 1 and 2). This NPP underestimation is largest in the California CS in the nearshore areas (34\% within $100 \mathrm{~km}$ from the coast) and in the open ocean water (up to $60 \%$ in the $500 \mathrm{~km}-1000 \mathrm{~km}$ offshore region) when compared to satellite-based estimates by Kahru et al. (2009). Similarly, simulated NPP in the Canary CS 

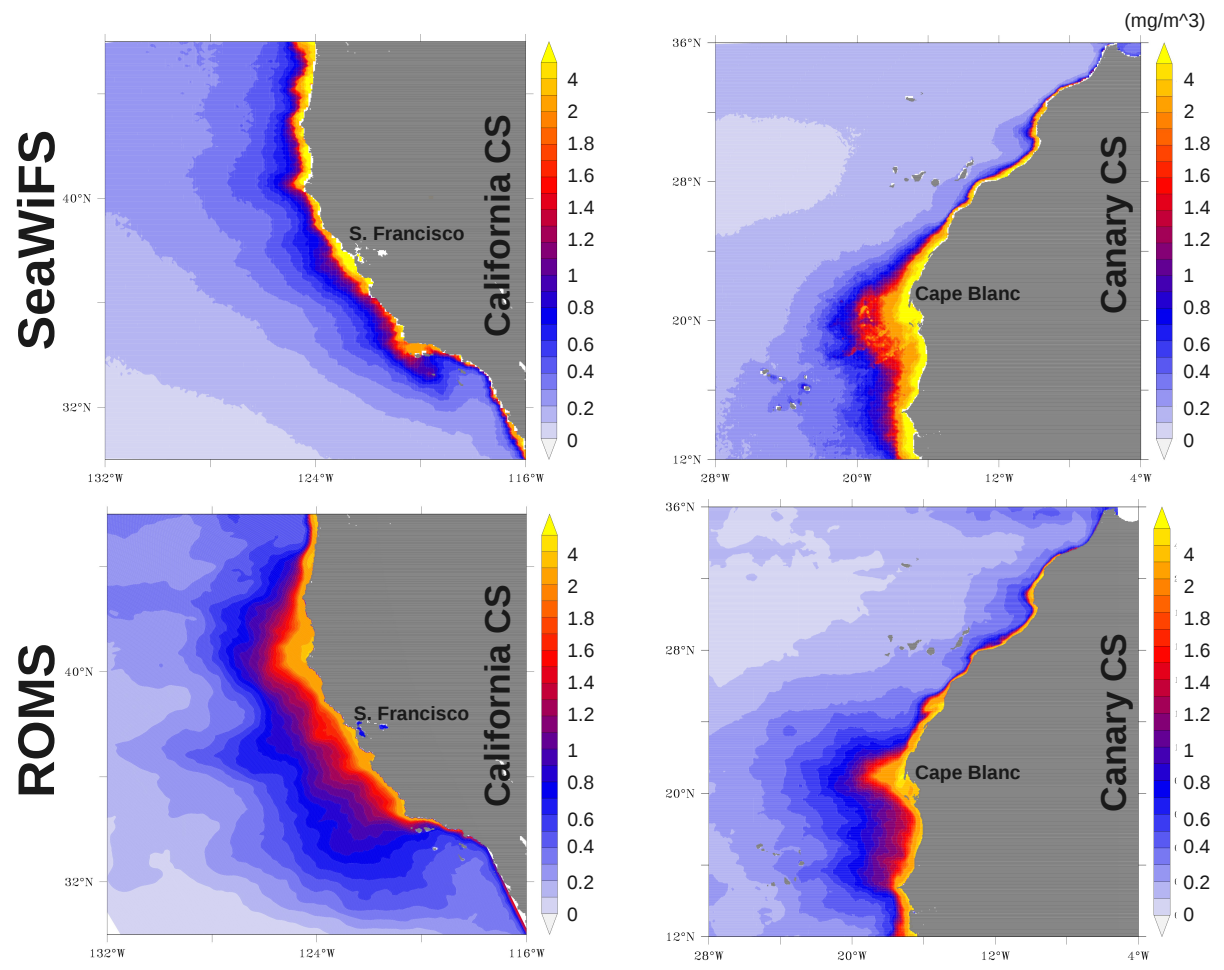

Fig. 1. Annual average of surface chlorophyll- $a$ concentrations $\left(\mathrm{mg} \mathrm{m}^{-3}\right)$ from SeaWiFS (top) and ROMS model (bottom) in the California CS (left) and the Canary CS (right). The SeaWiFS climatology is computed over the period from 1997 to 2007.
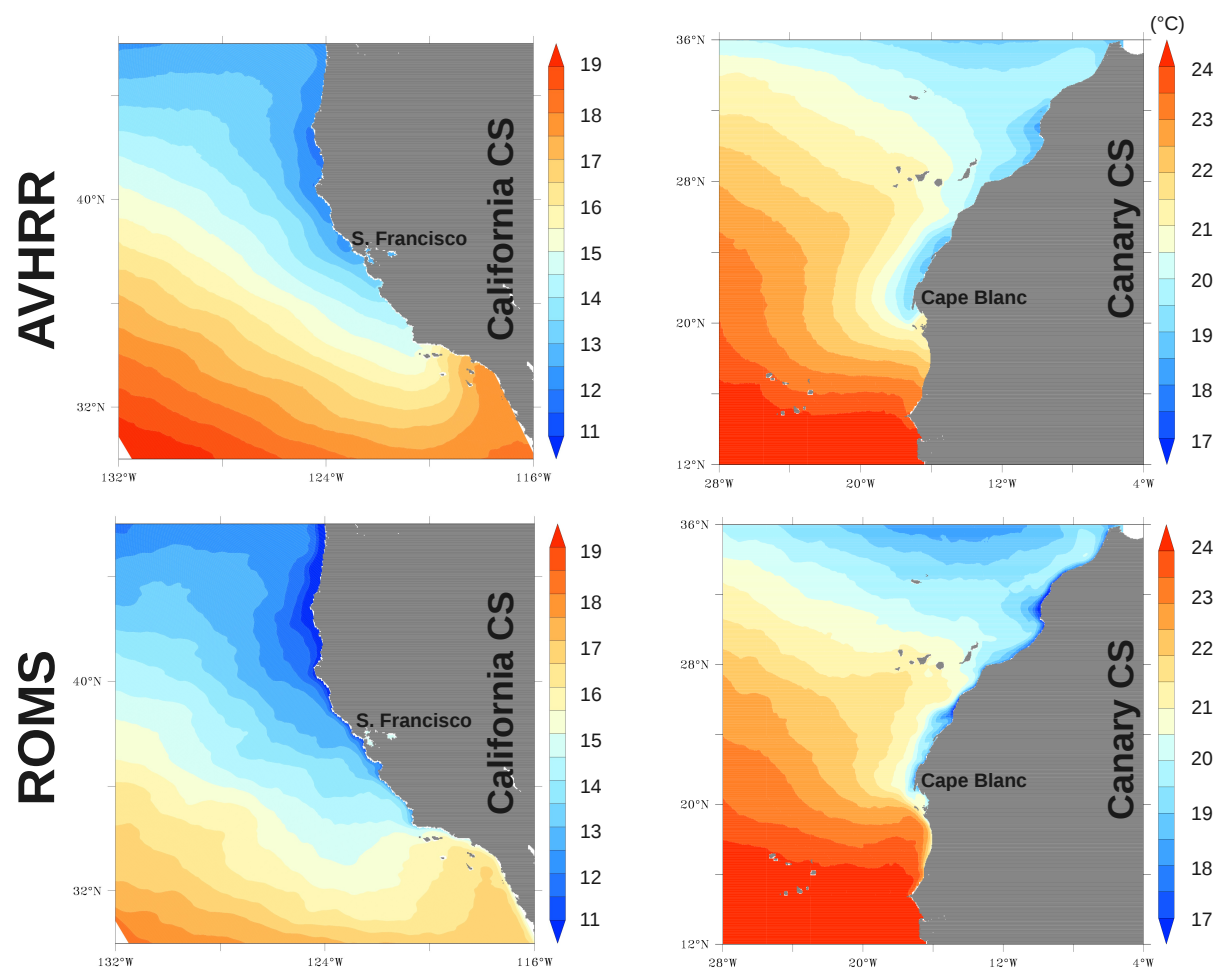

Fig. 2. Sea surface temperature (SST) annual average $\left({ }^{\circ} \mathrm{C}\right.$ ) from AVHRR (top) and ROMS model (bottom) in the California CS (left) and the Canary CS (right). The AVHRR observational climatology is computed over the period from 1997 to 2005. 

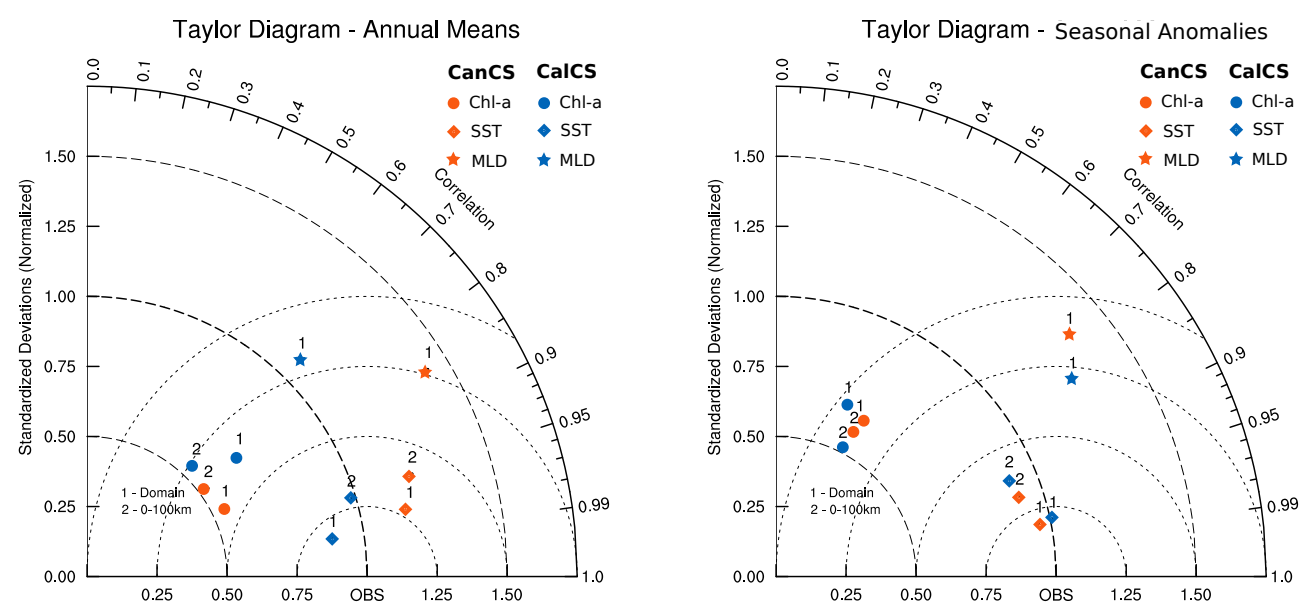

Fig. 3. Taylor (2001) diagrams of modeled annual-mean (left) and seasonal anomalies (right) of surface chlorophyll (circles), sea surface temperature (diamonds) and mixed layer depth (stars) in the California CS (blue) and the Canary CS (orange). The reference point of the Taylor diagram corresponds to SeaWiFS observations for chlorophyll, AVHRR data for temperature and the monthly climatology of de Boyer Montégut et al. (2004) for the mixed layer depth. The statistics were computed separately for the entire domain (data points labeled " 1 ") and the $100 \mathrm{~km}$ wide nearshore region (data points labeled " 2 ").

underestimates in-situ observation based estimates by over $20 \%$ (Tilstone et al., 2009).

Some of these deficiencies may arise from our using a simple NPZD-type ecosystem model as suggested by Gruber et al. (2006) for the underestimation of chlorophyll and NPP in the offshore regions. While the addition of increased biogeochemical and ecological complexity may indeed help, experience shows little gain in model skill for bulk ecosystem properties such as chlorophyll and primary production (Friedrichs and Hofmann, 2001; Hood et al., 2003; Friedrichs et al., 2007). Additionally, it has been established that when their parameters are tuned for one type of ecosystems (e.g., EBUS in this study), the simplest NPZD models fit the data as well as those with multiple phytoplankton functional groups (Friedrichs et al., 2007). Moreover, biogeochemical model intercomparisons have revealed that biogeochemical variations tends to be dominated by the physical environment and depend less on ecosystem model complexity (Friedrichs et al., 2006).

Overall, the model exhibits reasonable skills in both upwelling systems. Most importantly, it captures well the strong differences in phytoplankton biomass and NPP that characterizes the California and Canary CS. Since the primary focus of our study here is to understand these differences, we consider the identified biases as acceptable, particularly since the biases in the two systems are of the same nature and go in the same direction.

\section{Results and discussion}

The Canary CS generally shows substantially higher annual NPP in comparison to the California CS, with the former hav-
Table 1. Comparison of simulated and satellite observation-based estimates of net primary production $\left(\mathrm{mol} \mathrm{C} \mathrm{m}^{-2} \mathrm{yr}^{-1}\right)$ from Kahru et al. (2009) in the central California CS $\left(34^{\circ} \mathrm{N}-42^{\circ} \mathrm{N}\right)$.

\begin{tabular}{lcc}
\hline Offshore extent & $\begin{array}{c}\text { Kahru } \\
\text { satellite-based }\end{array}$ & $\begin{array}{c}\text { ROMS } \\
\text { model simulated }\end{array}$ \\
\hline $0-100 \mathrm{~km}$ & 32.9 & 21.6 \\
$100-500 \mathrm{~km}$ & 10.9 & 9.4 \\
$500-1000 \mathrm{~km}$ & 4.7 & 1.8 \\
\hline
\end{tabular}

Table 2. Comparison of simulated and in-situ estimates of net primary production $\left(\mathrm{mol} \mathrm{C} \mathrm{m}^{-2} \mathrm{yr}^{-1}\right.$ ) from Tilstone et al. (2009) over the Canary Current Coastal upwelling (CNRY) biogeochemical province $\left(15^{\circ} \mathrm{N}-26^{\circ} \mathrm{N}, 20^{\circ} \mathrm{W}\right.$-African coast $)$ as defined in Tilstone et al. (2009). Simulated NPP is shown at the $(N=6)$ observation point locations and over the whole CNRY biogeochemical province, respectively.

\begin{tabular}{ccc}
\hline $\begin{array}{c}\text { Tilstone } \\
\text { in-situ obs } \\
\text { Tilstone et al. (2009) }\end{array}$ & $\begin{array}{c}\text { ROMS } \\
\text { model simulated } \\
\text { at obs locations }\end{array}$ & $\begin{array}{c}\text { ROMS } \\
\text { model simulated } \\
\text { CNRY province }\end{array}$ \\
\hline 17.3 & 13.6 & 19.7 \\
\hline
\end{tabular}

ing on average more than $50 \%$ higher rates compared to the latter (Fig. 4). The largest simulated NPP is found south of Cape Bojador (around $26^{\circ} \mathrm{N}$ ) in the Canary CS and between $34^{\circ} \mathrm{N}$ and $38^{\circ} \mathrm{N}$ in the California CS. In absolute terms, annual NPP varies between 20 and $24 \mathrm{molCm}^{-2} \mathrm{yr}^{-1}$ in the nearshore areas of the central California and between 28 and 


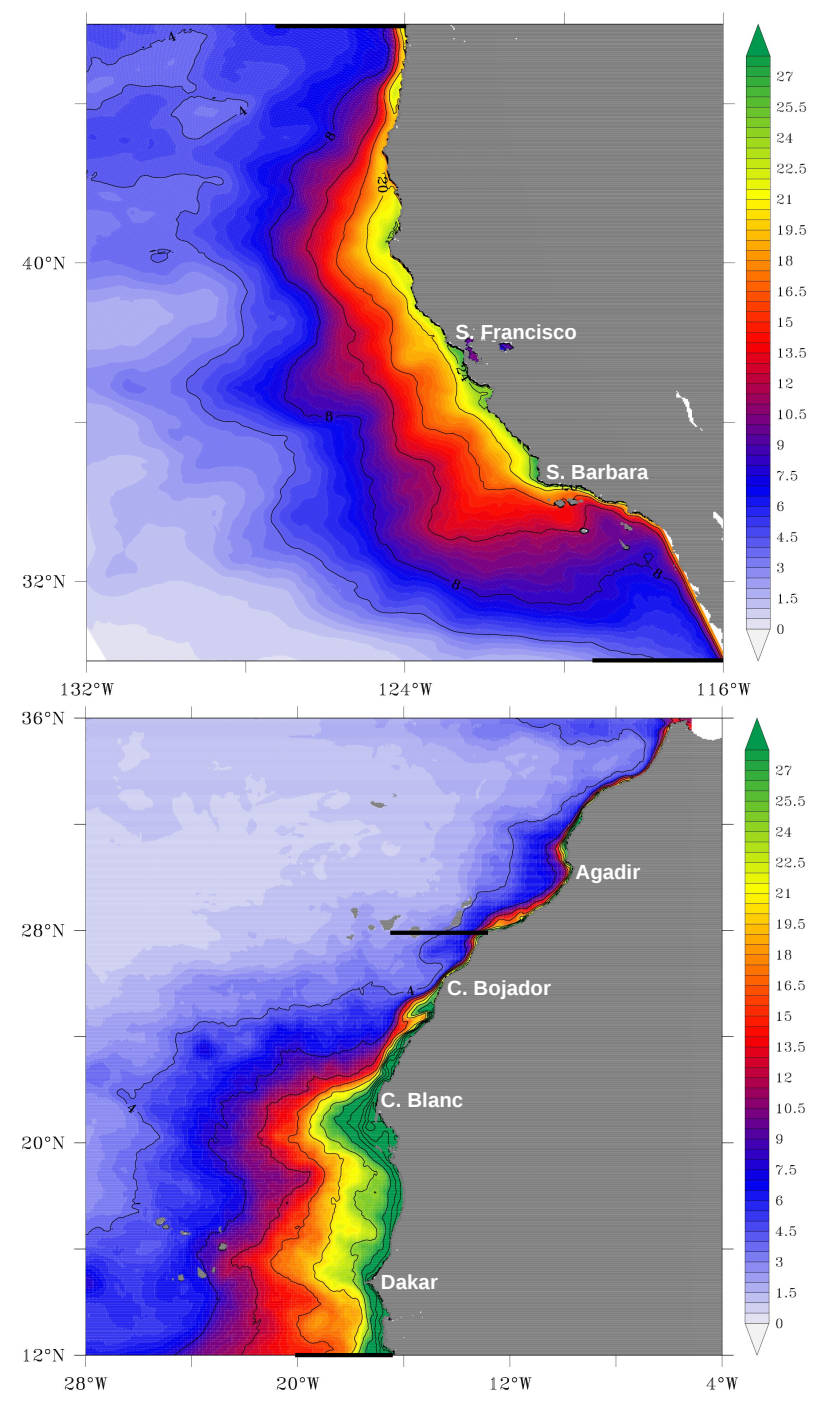

Fig. 4. Simulated annual mean, vertically integrated NPP $\left(\mathrm{mol} \mathrm{C} \mathrm{m}{ }^{-2} \mathrm{yr}^{-1}\right)$ in the California CS (left) and Canary CS (right).

$40 \mathrm{molCm}^{-2} \mathrm{yr}^{-1}$ in the nearshore areas of the Canary CS south of Cape Bojador. Although these rates are, on average, about $20 \%$ to $40 \%$ lower than corresponding in situ or satellite-based estimates, the model correctly simulates the large difference in NPP between the California CS and the Canary CS. Thus we will be using our model to investigate the mechanisms behind this difference.

According to Eq. (1), NPP is the product of the nutrient limitation term $\gamma\left(N_{\mathrm{n}}, N_{\mathrm{r}}\right)$, the nutrient-unlimited growth rate $\mu_{P}^{\max }(T, I)$ and the biomass $P$. Therefore, we need to examine each of these three components in order to understand the contrasting NPP between the two systems.

\subsection{Biological production and nutrient resources}

As the high biological production in EBUS is driven to the first order by the upwelling of nutrient-rich water to the sur-
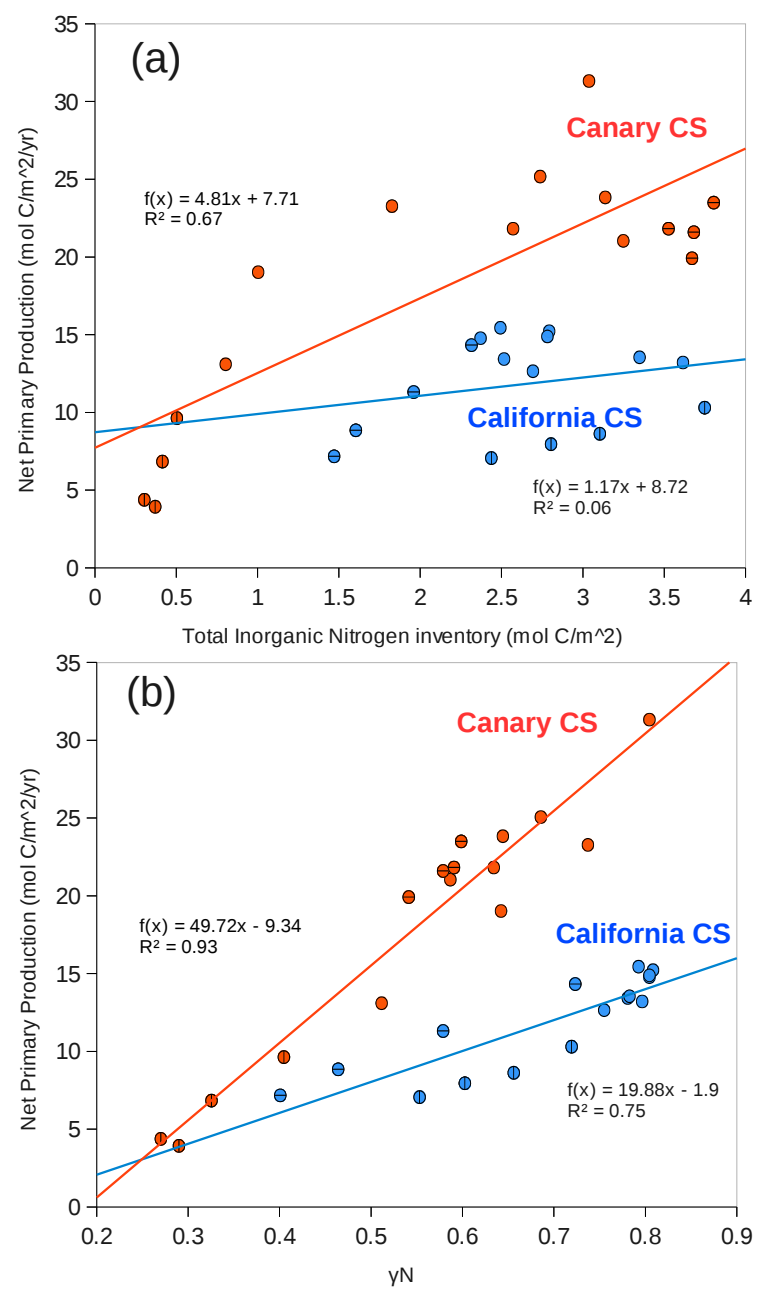

Fig. 5. (a) The relationship between NPP and the inventory of TIN in the euphotic zone in the California CS (blue) and Canary CS (orange). (b) NPP as a function of the nutrient limitation factor $\gamma\left(N_{\mathrm{n}}, N_{\mathrm{r}}\right)$ averaged over the upper $40 \mathrm{~m}$ in the California CS (blue) and Canary CS (orange). Data were averaged over the $300 \mathrm{~km}$ wide nearshore area and over $1^{\circ}$ bins in meridional direction. Circles with horizontal lines correspond to the southernmost part of each system, i.e., from $30^{\circ} \mathrm{N}$ to $34^{\circ} \mathrm{N}$ for the California CS and from $12^{\circ} \mathrm{N}$ to $16^{\circ} \mathrm{N}$ for the Canary $\mathrm{CS}$, and circles with vertical lines indicate their northernmost parts, i.e., from $42^{\circ} \mathrm{N}$ to $46^{\circ} \mathrm{N}$ for the California CS and from $24^{\circ} \mathrm{N}$ to $28^{\circ} \mathrm{N}$ for the Canary CS.

face, these differences may simply result from contrasting upwelling intensities between the two systems leading to different nutrient concentrations in the euphotic zone. To test this hypothesis, we examine here the relationship between NPP and the nutrient content in the euphotic zone in the two upwelling systems (Fig. 5a). To this end, we computed for each system the total inorganic nitrogen TIN (i.e., nitrate and ammonium) integrated vertically over the euphotic zone.

While annual NPP is $54 \%$ larger in the Canary CS relative to the California CS, the TIN concentrations are on average $18 \%$ larger in the latter (Table 3 ). This indicates that 
Table 3. Production and its drivers averaged over the $300 \mathrm{~km}$ wide nearshore area for the California CS and the Canary CS. $T_{\text {resid }}$ refers to the water residence time in the $100 \mathrm{~km}$ wide nearshore area. $\mu_{P}$ and $\mu_{P}^{\max }$ refer to the growth rate and nutrient-replete growth rate, respectively. Nutrient-replete growth rates $\mu_{P}^{\max }$ are normlized to constant $\mathrm{PAR}=20 \mathrm{~W} \mathrm{~m}^{-2}, \theta=25 \mathrm{mg} \mathrm{C}(\mathrm{mg} \mathrm{chl}-a)^{-1}$ and $T=14{ }^{\circ} \mathrm{C}$, respectively.

\begin{tabular}{|c|c|c|c|c|c|c|c|c|}
\hline Unit & $\begin{array}{c}\mathrm{NPP} \\
\mathrm{mol} \mathrm{C} \mathrm{m}^{-2} \mathrm{yr}^{-1}\end{array}$ & $\begin{array}{c}\text { TIN } \\
\mathrm{mol} \mathrm{C} \mathrm{m}^{-2}\end{array}$ & $\begin{array}{c}T_{\text {resid }} \\
\text { day }\end{array}$ & $\begin{array}{c}\mu_{P} \\
\mathrm{day}^{-1}\end{array}$ & $\begin{array}{l}\mu_{P}^{\max } \\
\text { day }^{-1}\end{array}$ & $\begin{array}{c}\mu_{P}^{\max } \\
(I=\text { const }) \\
\text { day }^{-1}\end{array}$ & $\begin{array}{c}\mu_{P}^{\max } \\
(\theta=\text { const }) \\
\text { day }^{-1}\end{array}$ & $\begin{array}{c}\mu_{P}^{\max } \\
(T=\text { const }) \\
\text { day }^{-1}\end{array}$ \\
\hline California CS & 11.8 & 2.63 & 19.29 & 0.32 & 0.46 & 0.45 & 0.52 & 0.46 \\
\hline Canary CS & 18.15 & 2.17 & 30.1 & 0.36 & 0.64 & 0.42 & 0.83 & 0.57 \\
\hline Relative diff. & $+54 \%$ & $-18 \%$ & $+56 \%$ & $+12 \%$ & $+40 \%$ & $-7 \%$ & $+60 \%$ & $+24 \%$ \\
\hline
\end{tabular}

Table 4. Seasonally averaged NPP $\left(\mathrm{mol} \mathrm{m} \mathrm{m}^{-2} \mathrm{yr}^{-1}\right), \mathrm{TIN}\left(\mathrm{mol} \mathrm{m} \mathrm{m}^{-2}\right)$ and nutrient assimilation rate (i.e., NPP/TIN in $\left.\mathrm{yr}^{-1}\right)$ in the euphotic zone in the California CS and Canary CS.

\begin{tabular}{llcccc}
\hline & & $\begin{array}{c}\text { Winter } \\
\text { (Jan-Feb-Mar) }\end{array}$ & $\begin{array}{c}\text { Spring } \\
\text { (Apr-May-Jun) }\end{array}$ & $\begin{array}{c}\text { Summer } \\
\text { (Jul-Aug-Sep) }\end{array}$ & $\begin{array}{c}\text { Automn } \\
\text { (Oct-Nov-Dec) }\end{array}$ \\
\hline California CS & NPP & 8.76 & 14.17 & 16.04 & 8.41 \\
& TIN & 2.1 & 2.14 & 3.09 & 3.18 \\
& NPP/TIN & 4.17 & 6.62 & 5.19 & 2.64 \\
Canary CS & NPP & 21.52 & 24.32 & 15.36 & 11.57 \\
& TIN & 2.29 & 2.67 & 1.98 & 1.74 \\
& NPP/TIN & 9.40 & 9.11 & 7.76 & 6.65 \\
\hline
\end{tabular}

the nutrients are used much more efficiently in the Canary CS relative to the California CS despite the former having actually a higher upwelling intensity, on average (Lachkar and Gruber, 2011; Gruber et al., 2011). Thus, our model results indicate that the reality is more complex than the simple canonical view of higher upwelling giving rise to higher nutrient availability, yielding higher growth rates and ultimately higher NPP. This perplexing finding emerges not only from the analysis of the annual mean, but also when the analysis is repeated with monthly outputs (Table 4).

In both systems and particularly in the California CS, the relationship between the NPP and TIN exhibits a strong nonlinearity, with a tendency for saturation of NPP at high nutrient concentrations (Fig. 5a). A part of this non-linearity is due to the Michaelis-Menten nutrient limitation formulation, which is strongly non-linear with respect to nutrient concentrations. Thus, to better describe the relationship between NPP and the "useful" nutrient resources, we show in Fig. 5b NPP as a function of the nutrient limitation factor $\gamma\left(N_{\mathrm{n}}, N_{\mathrm{r}}\right)$. The slopes of a linear regression of NPP on the nutrient limitation factor $\gamma\left(N_{\mathrm{n}}, N_{\mathrm{r}}\right)$ are $20( \pm 7) \mathrm{mol} \mathrm{C} \mathrm{m}^{-2} \mathrm{yr}^{-1}$ for the California CS and $50( \pm 8) \mathrm{molCm}^{-2} \mathrm{yr}^{-1}$ for the Canary CS. The more than a factor of two difference in these slopes which represent the product $\mu_{P}^{\max }(T, I) \times P$ indicates that these two parameters, i.e., the nutrient-replete growth rate $\mu_{P}^{\max }(T, I)$ and the biomass $P$ are important drivers for explaining the differing levels of NPP between the Canary and
California CS. Next, we first investigate the contribution of the phytoplankton growth under nutrient-replete conditions and then the contribution of the biomass.

\subsection{The nutrient-replete growth rate}

The comparison of the two systems reveals that the nutrientreplete growth rate $\mu_{P}^{\max }(T, I)$ is, on average, $40 \%$ faster in the Canary CS than in the California CS (Table $3 \&$ Fig. 6). As described by Eq. (3), $\mu_{P}^{\max }(T, I)$ is a function of light, temperature and the dynamic chlorophyll-to-carbon ratio $\theta$. In order to better understand the contribution of each of these three factors to the overall difference in $\mu_{P}^{\max }(T, I)$ between the two systems, we consider normalized $\mu_{P}^{\max }(T, I)$ distributions with respect to light, the chlorophyll-to-carbon ratio, and temperature, respectively (Fig. 6).

When normalized to a constant PAR of $20 \mathrm{Wm}^{-2}$, which corresponds to the average light conditions in the central California CS, the normalized nutrient-replete growth rate is actually smaller in the Canary CS compared to that in the California CS (Table 3). That is, if both systems were exposed to identical light conditions, the nutrient-replete growth $\mu_{P}^{\max }(T, I)$ in the California CS would slightly exceed that from the Canary CS. This indicates a dominant role of the light resources in the contrasting nutrient-replete growth rates between the two systems. The large magnitude of light control on $\mu_{P}^{\max }(T, I)$ is, however, attenuated 

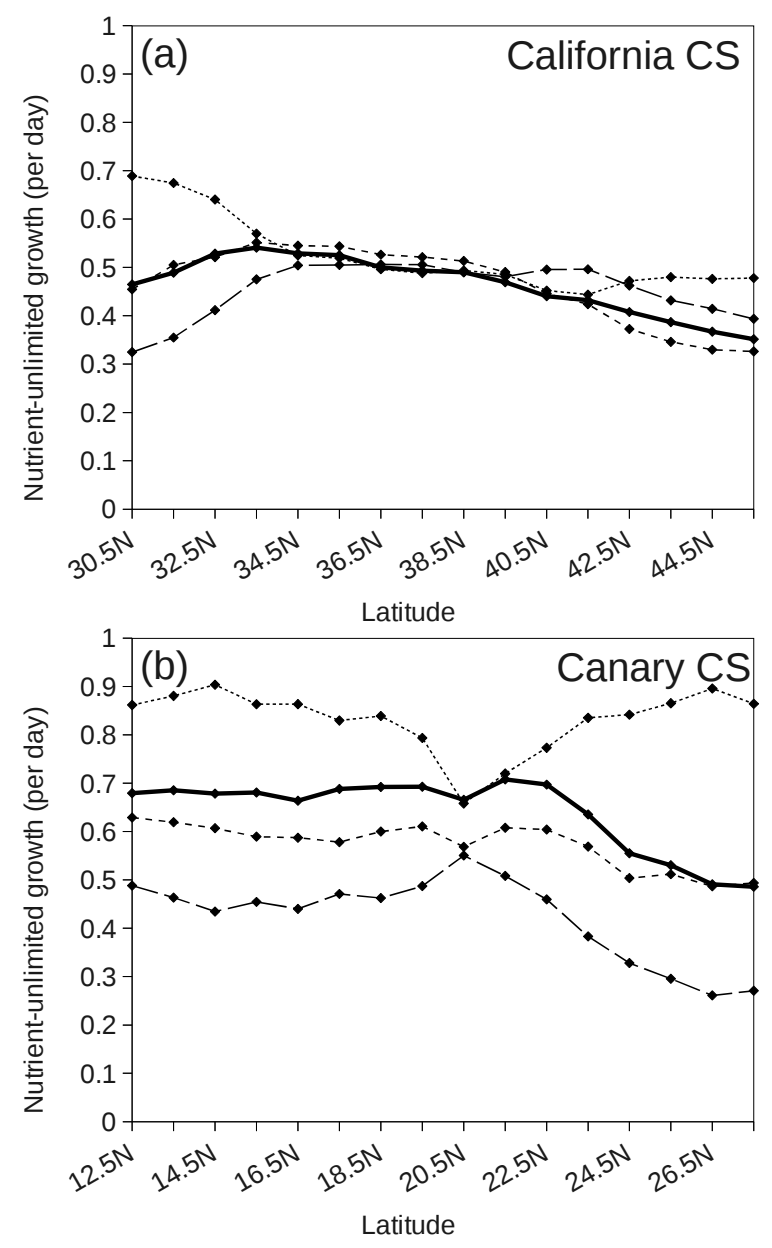

Fig. 6. Meridional distribution of the temperature-dependent, lightlimited growth rate under nutrient replete conditions $\mu_{P}^{\max }(T, I)$ in the California CS (a) and the Canary CS (b). Data is horizontally averaged over the $300 \mathrm{~km}$ wide nearshore area and vertically over the upper $40 \mathrm{~m}$. Shown are the simulated $\mu_{P}^{\max }(T, I)$ (solid) and normalized $\mu_{P}^{\max }(T, I)$ to to constant PAR $=20 \mathrm{~W} \mathrm{~m}^{-2}$ (long dashed), temperature $T=14^{\circ} \mathrm{C}$ (fine dashed) and chlorophyll-tocarbon ratio $\theta=25 \mathrm{mg} \mathrm{C}(\mathrm{mg} \mathrm{Chl}-a)^{-1}$ (dotted).

by the chlorophyll-to-carbon ratio variations allowed in our model, which mimic photoacclimation in phytoplankton (Falkowski and Raven, 1997). Fixing $\theta$ for example at 25 $\mathrm{mgC}(\mathrm{mgChl}-a)^{-1}$, which corresponds to the average conditions in the central California CS, enhances indeed the difference in $\mu_{P}^{\max }(T, I)$ between the two systems by more than $50 \%$ (Table 3). Finally, when normalized to a constant temperature of $14^{\circ} \mathrm{C}$ (corresponding to the average temperature conditions in the central California CS), the difference in $\mu_{P}^{\max }(T, I)$ between the two systems gets reduced by $38 \%$, which indicates a smaller, yet important role played by the temperature differences in the contrasting nutrient-replete growth rates between the two upwelling systems (Table 3).

The $40 \%$ larger $\mu_{P}^{\max }$ in the Canary CS causes the overall growth rate $\mu_{P}$ to be $12 \%$ larger in this system, despite a

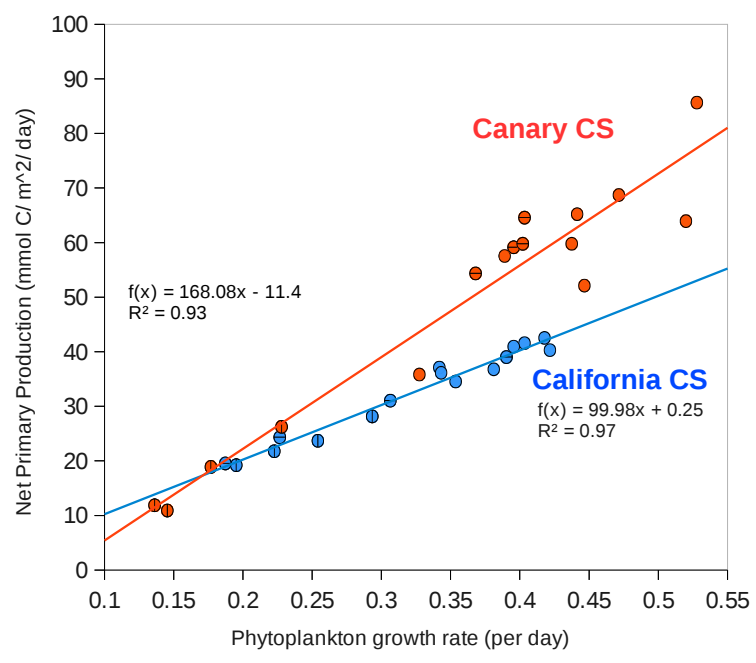

Fig. 7. The relationship between NPP and the phytoplankton growth rate in the California CS (blue) and Canary CS (orange). Data were averaged over the $300 \mathrm{~km}$ wide nearshore area and over $1^{\circ}$ bins in meridional direction. Circles with horizontal lines correspond to the southernmost part of each system, i.e., from $30^{\circ} \mathrm{N}$ to $34^{\circ} \mathrm{N}$ for the California CS and from $12^{\circ} \mathrm{N}$ to $16^{\circ} \mathrm{N}$ for the Canary $\mathrm{CS}$, and circles with vertical lines indicate their northernmost parts, i.e., from $42^{\circ} \mathrm{N}$ to $46^{\circ} \mathrm{N}$ for the California $\mathrm{CS}$ and from $24^{\circ} \mathrm{N}$ to $28^{\circ} \mathrm{N}$ for the Canary CS.

stronger nutrient limitation (Table 3). Does this difference alone explain the more than $50 \%$ larger NPP in the Canary CS relative to the California CS? To answer this question, we next consider the effect of the third component in Eq. (1), i.e., the phytoplankton biomass, on the production in the two upwelling systems.

\subsection{NPP and phytoplankton biomass}

The correlation between the NPP and the total growth rate is very strong in both systems with $R^{2}$ of 0.93 and 0.97 in the Canary and the California systems, respectively. Yet, comparable growth rates in the Canary CS and the California CS lead to substantially different NPP (Fig. 7). The slopes of a linear regression of NPP on the growth rate vary from $100( \pm 10) \mathrm{molCm}^{-2}$ for the California CS to up to 168 $( \pm 28) \mathrm{molCm}^{-2}$ for the Canary CS. Since the slope is equal to the average biomass $P$, this difference indicates a significantly larger average biomass in the Canary CS relative to the California CS even at comparable growth rates. Therefore, in addition to the slightly faster phytoplankton growth in the Canary CS relative to the California CS, mechanisms affecting the biomass but independent of the growth rate must contribute to the large NPP contrasts between the two systems.

According to Eq. (1), we can write the time-evolution of the phytoplankton biomass as:

$\frac{d P}{d t}=\left[\mu_{P}\left(T, I, N_{\mathrm{n}}, N_{\mathrm{r}}\right)-\Phi^{\mathrm{graz}}(P, Z)\right.$ 

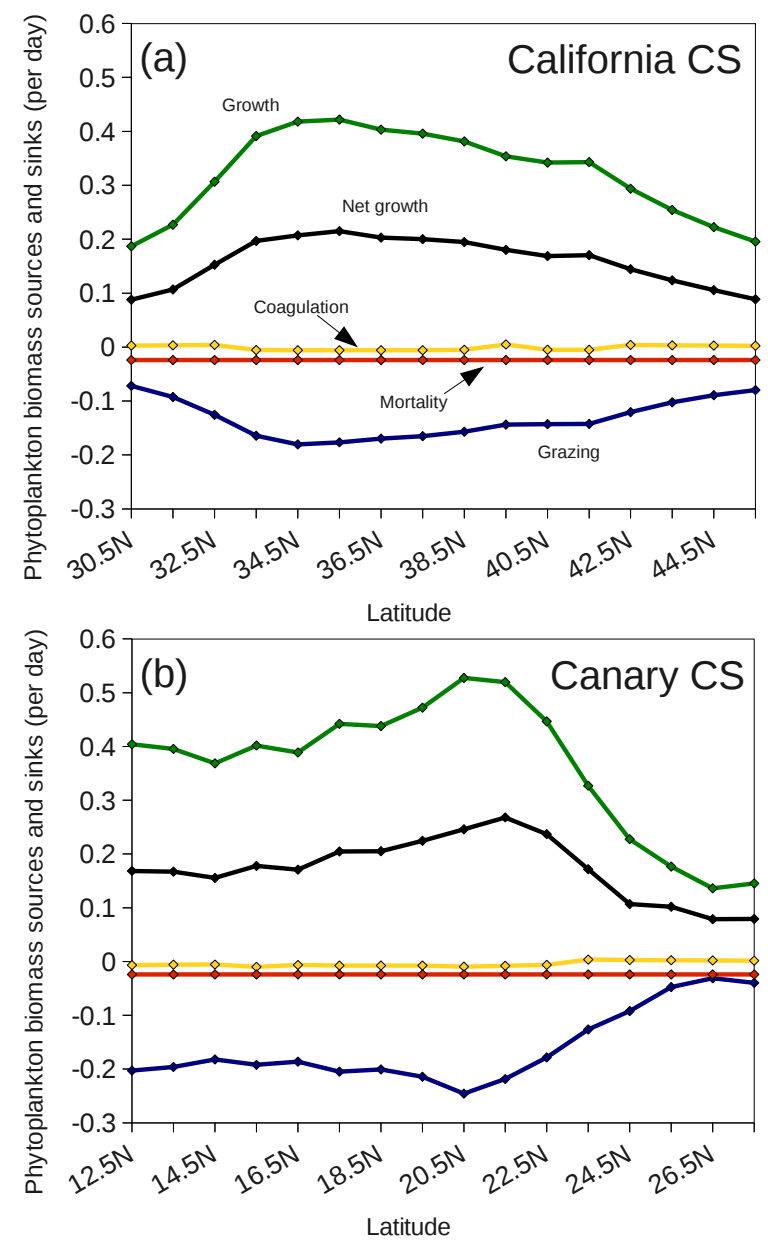

Fig. 8. Meridional distribution of the net growth of phytoplankton (black) and its four components: the growth (green), the grazing (blue), the mortality (red) and the coagulation (yellow) daily rates in the California CS (a) and the Canary CS (b). Data is horizontally averaged over the $300 \mathrm{~km}$ wide nearshore area and vertically over the upper $40 \mathrm{~m}$.

$$
\left.-\Phi^{\text {mort }}-\Phi^{\text {coag }}\left(P, D_{S}\right)\right] \cdot P+\Lambda(P)
$$

where the term between square brackets on the right-hand side represents the net growth, i.e., growth minus the biological sink terms, and $\Lambda(P)$ is the physical transport operator. Because of their very small magnitude, the phytoplankton mortality and the coagulation terms contribute very little to the net growth. Thus, the net growth is essentially set by the balance between phytoplankton growth and the grazing by zooplankton (Fig. 8). Moreover, because the grazing term $\Phi^{\text {graz }}(P, Z)$ is tightly correlated in our model with the growth rate $\mu_{P}\left(T, I, N_{\mathrm{n}}, N_{\mathrm{r}}\right)\left(R^{2}>0.95\right)$ (Fig. 9a), we can express the net growth as being nearly proportional to the phytoplankton growth (Fig 9b).

Therefore, if we consider an individual water particle and follow it through time in a Lagrangian framework, Eq. (6)
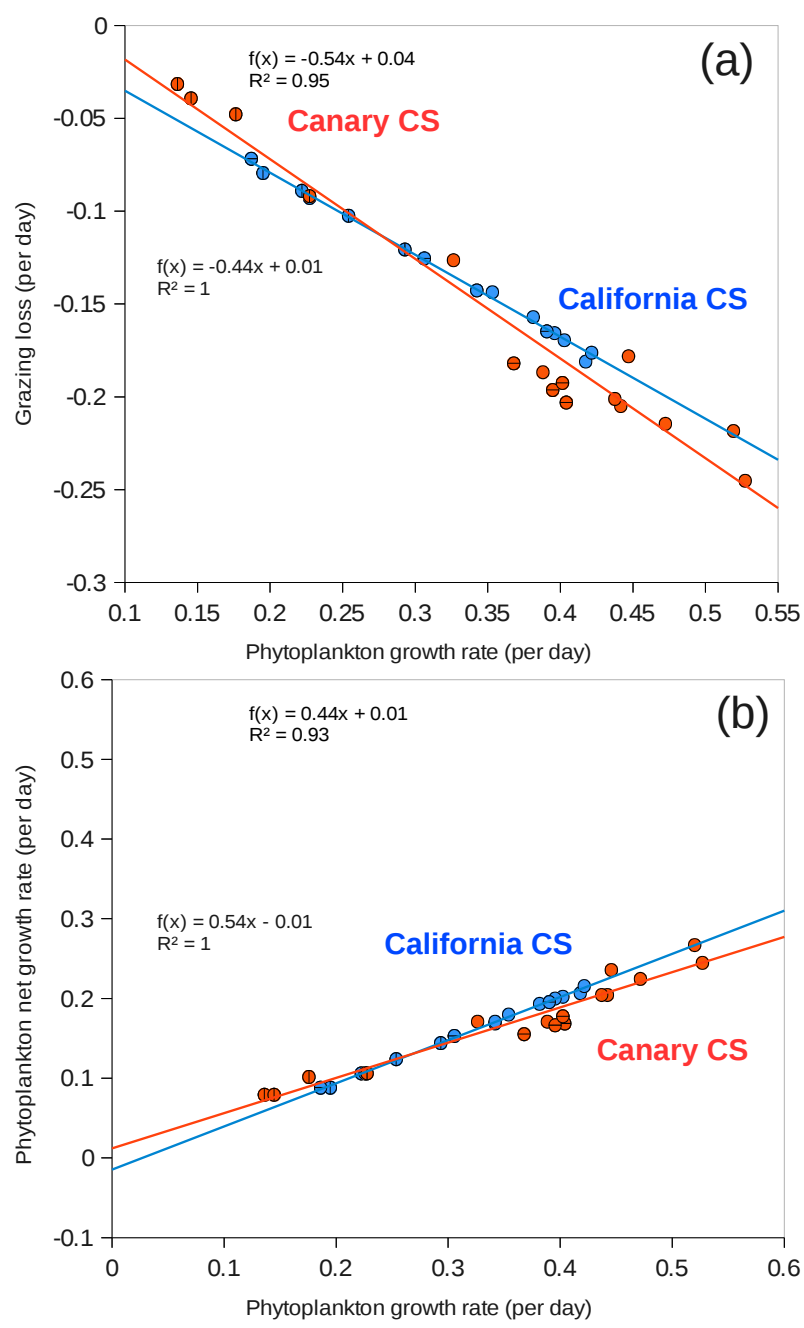

Fig. 9. (a) The grazing rate as a function of the growth rate in the California CS (blue) and Canary CS (orange). (b) The net growth rate as a function of the growth rate in the California CS (blue) and Canary CS (orange). Data were averaged over the $300 \mathrm{~km}$ wide nearshore area and over $1^{\circ}$ bins in meridional direction. Circles with horizontal lines correspond to the southernmost part of each system, i.e., from $30^{\circ} \mathrm{N}$ to $34^{\circ} \mathrm{N}$ for the California CS and from $12^{\circ} \mathrm{N}$ to $16^{\circ} \mathrm{N}$ for the Canary $\mathrm{CS}$, and circles with vertical lines indicate their northernmost parts, i.e., from $42^{\circ} \mathrm{N}$ to $46^{\circ} \mathrm{N}$ for the California CS and from $24^{\circ} \mathrm{N}$ to $28^{\circ} \mathrm{N}$ for the Canary CS.

can be simplified to:

$\frac{d P}{d t} \approx \alpha \cdot \mu_{P}\left(T, I, N_{\mathrm{n}}, N_{\mathrm{r}}\right) \cdot P$,

where $\alpha$ is a proportionality factor. This is a first order ordinary differential equation that can be solved if the Lagrangian time-evolution of the growth rate is known. In the idealized case where the growth rate remains constant within the narrow upwelling zone the solution of Eq. (7), i.e., $P(t)$ is an exponential function with the exponent given by the growth rate 
and the residence time $t_{\text {res }}$ of the water parcel in the coastal zone.

Therefore, it appears that the previously shown partial decoupling between the growth rate on the one hand and the phytoplankton biomass and NPP on the other hand can result from contrasting residence times in the nearshore area between the two upwelling systems. NPP may indeed remain low despite high growth rates, as the short residence times would prevent the buildup of high phytoplankton biomass. Conversely, long water residence times in the nearshore area can result in a relatively large buildup of biomass, thereby permitting high NPP even at moderate growth rates.

Next, we investigate how water residence times in the nearshore vary between and within these systems, and we explore the potential mechanisms responsible for these variations as well as the impact this has on the recycling and export of nutrients and organic matter.

\subsection{Nearshore water residence times}

The buildup of biomass in the upwelling zone is a function of the water renewal rate, i.e. the inverse of the residence time, in the nearshore area. To determine the water mass residence times in the upwelling zone, a large number of virtual particles were launched in this region and their Lagrangian trajectories computed using ARIANE (Blanke and Raynaud, 1997), a Lagrangian diagnostic tool fully documented at http://stockage.univ-brest.fr/ grima/Ariane/doc.html. In order to obtain a good sampling of newly upwelled waters, we seeded each grid point in the near-surface (upper $10 \mathrm{~m}$ ) and within the $50 \mathrm{~km}$ wide coastal strip. Repeating this particle release experiment each 5 days throughout the year led to more than 300000 particle trajectories in each of the two upwelling systems. Based on these large populations of individual trajectories, we statistically estimated the residence times of newly upwelled water masses in the $100 \mathrm{~km}$ wide nearshore area. Because long residence times outside the growing season have little impact on biomass and NPP, we computed for each upwelling system the NPP weighted annual mean residence time. This gives a (weighted) average residence time of the newly upwelled water of $30( \pm 15)$ days in the nearshore area of the Canary CS, which is more than $55 \%$ longer compared to the residence time found in the California CS of $19( \pm 7)$ days (Fig. 10 and Table 3). Even in the unweighted average case, the difference remains substantial (about 20\%).

The longer water residence times enhance the buildup of biomass in the Canary CS coastal zone, leading to a substantially larger production in comparison with the California CS. Conversely, the substantially shorter water residence times in the nearshore region of the California CS result in an overall lower average biomass, thereby contributing to lowering the production in this system. Next, we explore the mechanisms potentially responsible for the identified contrasts in water residence times between the two systems.
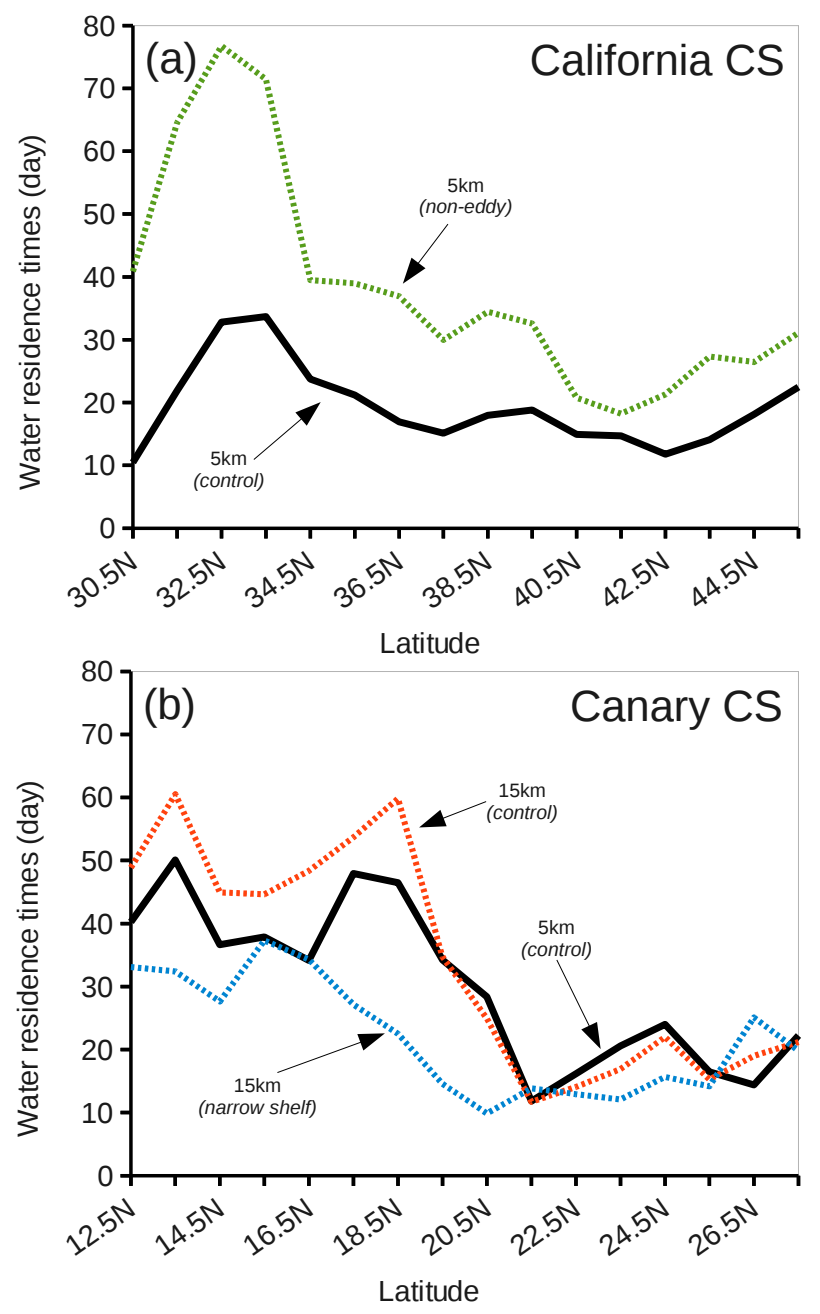

Fig. 10. (a) Meridional distribution of the water residence times in the $100 \mathrm{~km}$ wide nearshore area in the California CS as simulated in the control simulation (solid black) and the non-eddy simulation (dashed green). (b) Meridional distribution of the water residence times in the $100 \mathrm{~km}$ wide nearshore area in the Canary CS as simulated in the control $5 \mathrm{~km}$ simulation (solid black), the $15 \mathrm{~km}$ simulation with unaltered topography (dashed orange) and the $15 \mathrm{~km}$ narrowed-shelf simulation (dashed blue).

\subsection{The role of mesoscale activity and shelf topography}

The longer water residence time in the Canary CS relative to the California CS has likely no single explanation. Both the shelf topography and the level of mesoscale activity probably contribute (Marchesiello and Estrade, 2009; Gruber et al., 2011). In order to test these hypotheses, we undertook three additional simulations. First, to evaluate the control of mesoscale activity on the nearshore water residence times, we compare our control California CS simulation to analogous simulation where the momentum equation was linearized in such a way to suppress the eddydriven transport in the model (Fig. 10a) (see Gruber et al. (2011) for details on this modification). The water residence 


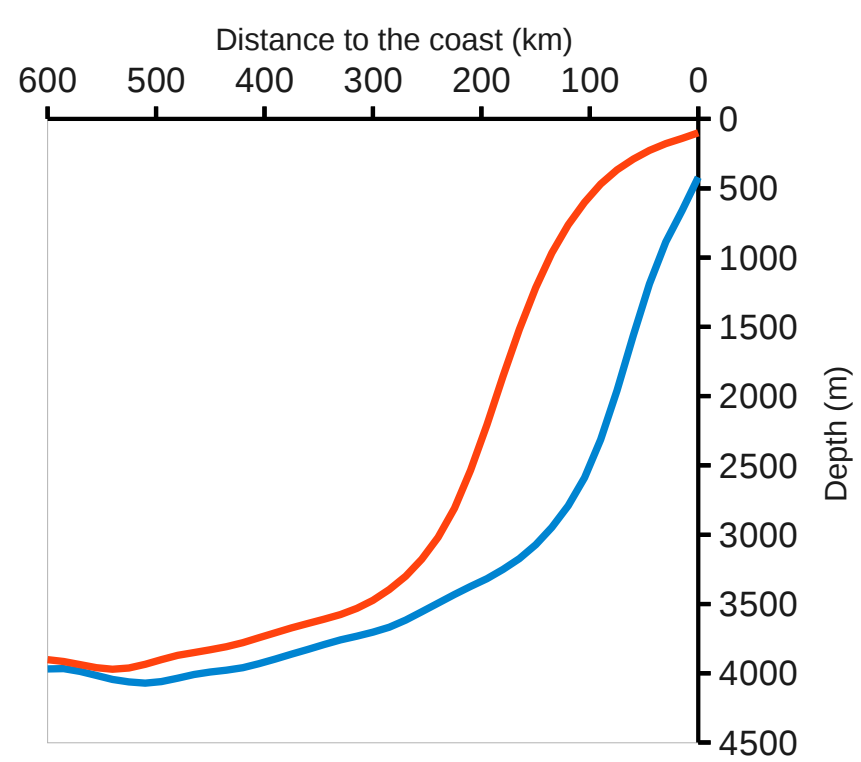

Fig. 11. Alongshore averaged bottom topography depth as a function of distance to the coast in the the Canary CS $15 \mathrm{~km}$ simulation with unaltered topography (orange) and the $15 \mathrm{~km}$ narrowed-shelf simulation (blue).

times in the nearshore area are on average twice as long in the non-eddying simulation in comparison to the control (eddying) simulation. This confirms the important role exerted by mesoscale activity in enhancing the offshore export and limiting the local buildup of biomass, in-line with the findings of Gruber et al. (2011) who demonstrated that mesoscale processes increase the transport of nutrient and organic carbon from the nearshore into the open ocean. Second, to test the role of wide continental shelves in increasing water residence times, we made two additional Canary CS simulations at slightly coarser horizontal resolution of $15 \mathrm{~km}$ : (i) one simulation where all the settings are kept identical to the control $5 \mathrm{~km}$ simulation, and (ii) a second simulation where the initially wide continental shelf was substantially narrowed by altering the nearshore bottom topography (Fig. 11). The $15 \mathrm{~km}$ Canary CS simulation with unaltered topography shows on average a $12 \%$ longer residence times in comparison to the $5 \mathrm{~km}$ simulation (Fig. 10b). This is consistent with our previous finding that lower eddy activity leads to longer residence times in the nearshore area of EBUS. In the narrowed continental shelf simulation, the water residence times get, however, substantially reduced by $35 \%$ on average (Fig. 10b). This confirms the role of wide continental shelves in enhancing the local recycling and limiting the offshore export of nutrients and biomass. Our result is consistent with previous theoretical and model-based findings by Austin and Lentz (2002) and Marchesiello and Estrade (2009). Next, we investigate the consequences of these differences for the recycling and export of nutrients and organic matter in the two upwelling systems.

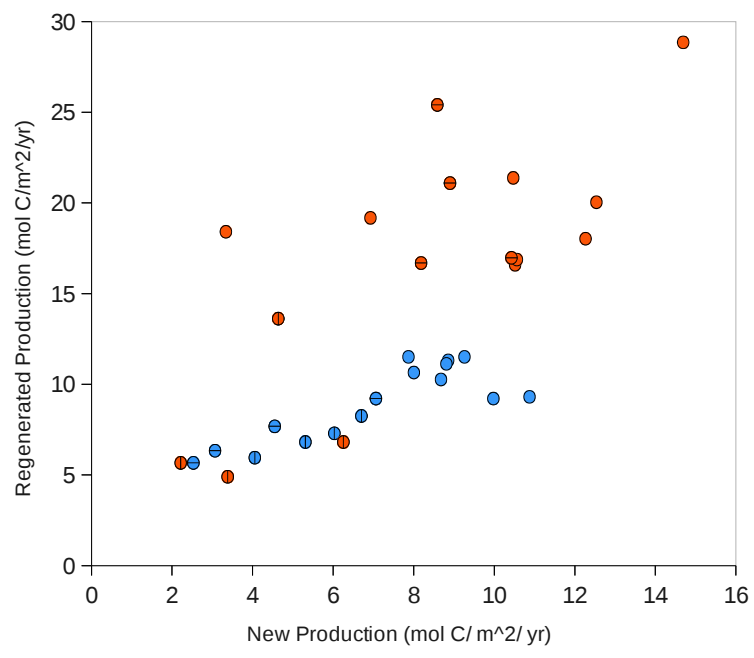

Fig. 12. The relationship between the regenerated production and the new production in the California CS (blue) and Canary CS (orange). Data were averaged over the $100 \mathrm{~km}$ wide nearshore area and over $1^{\circ}$ bins in meridional direction. Circles with horizontal lines correspond to the southernmost part of each system, i.e., from $30^{\circ} \mathrm{N}$ to $34^{\circ} \mathrm{N}$ for the California $\mathrm{CS}$ and from $12^{\circ} \mathrm{N}$ to $16^{\circ} \mathrm{N}$ for the Canary CS, and circles with vertical lines indicate their northernmost parts, i.e., from $42^{\circ} \mathrm{N}$ to $46^{\circ} \mathrm{N}$ for the California $\mathrm{CS}$ and from $24^{\circ} \mathrm{N}$ to $28^{\circ} \mathrm{N}$ for the Canary CS.

\subsection{Recycling and export of nutrients and organic matter}

The inefficient use of nutrients combined with a relatively high offshore export of biomass leads in the California CS relative to the Canary CS to a much lower recycling of nutrients in the nearshore area, and thus to a much higher f-ratio, i.e., the ratio of new production to net primary production. Fig. 12 shows the regenerated production as a function of the new production averaged over the first $100 \mathrm{~km}$ from the coast in both systems. While new production is only $15 \%$ lower in the California CS in comparison with the Canary CS, regenerated production is nearly $50 \%$ lower, leading to a substantially larger f-ratio in the California CS (0.44) relative to the Canary CS (0.33).

Numerically equating new and export production when averaged over large spatial and temporal scales is common practice, given the relative ease with which new production measurements can be obtained (Eppley and Peterson, 1979). Yet, more recent studies revealed that these two fluxes can become spatially decoupled in coastal upwelling systems because of substantial lateral transport of newly produced organic matter (Berger et al., 1989; Plattner et al., 2005). Given the substantial differences found between the California and the Canary systems in terms of water residence times in the nearshore, we explore here how the relationship of export production to new production varies between these two systems. 

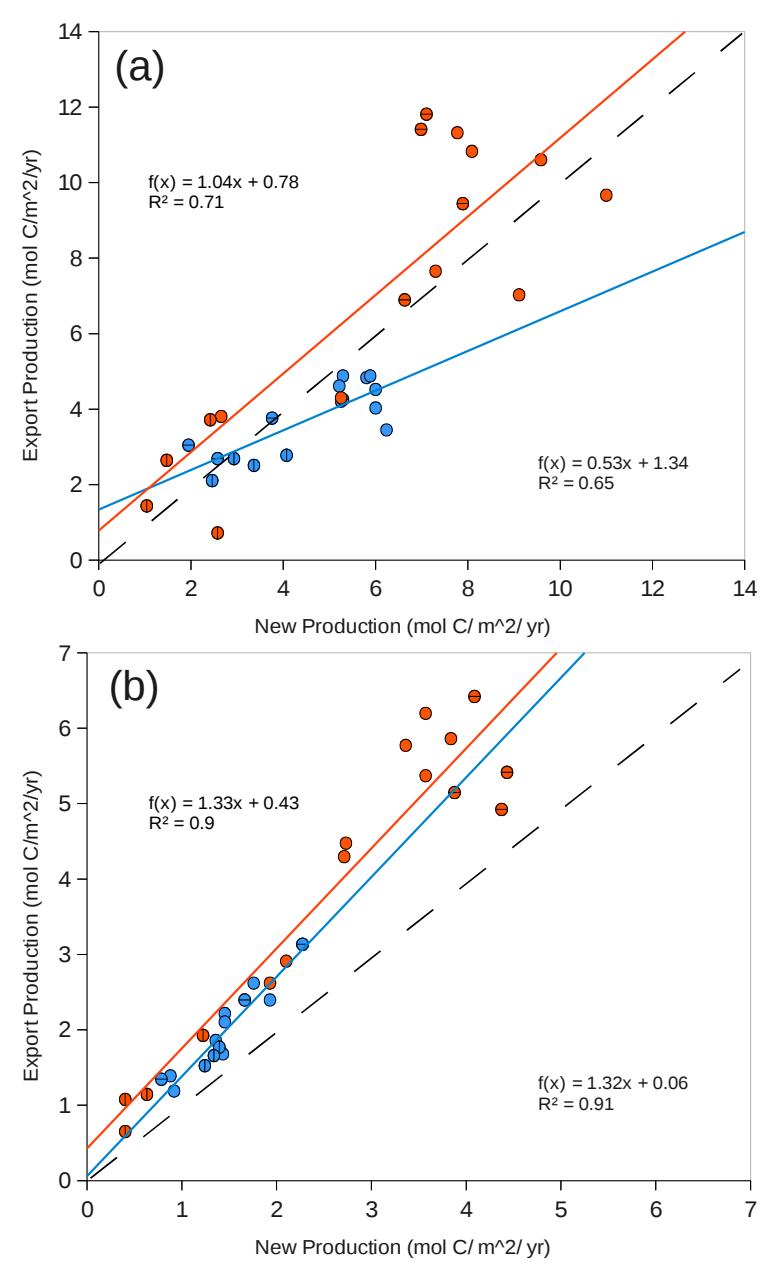

Fig. 13. Export production as a function of new production in the California CS (blue) and Canary CS (orange) averaged (a) over the $300 \mathrm{~km}$ wide nearshore area and (b) between $300 \mathrm{~km}$ and $500 \mathrm{~km}$ offshore. Data were averaged over $1^{\circ}$ bins in meridional direction. Circles with horizontal lines correspond to the southernmost part of each system, i.e., from $30^{\circ} \mathrm{N}$ to $34^{\circ} \mathrm{N}$ for the California CS and from $12^{\circ} \mathrm{N}$ to $16^{\circ} \mathrm{N}$ for the Canary CS, and circles with vertical lines indicate their northernmost parts, i.e., from $42^{\circ} \mathrm{N}$ to $46^{\circ} \mathrm{N}$ for the California CS and from $24^{\circ} \mathrm{N}$ to $28^{\circ} \mathrm{N}$ for the Canary CS. The diagonal dashed grey line indicate the identity line.

In the California CS, total export production is generally smaller than new production over the first $300 \mathrm{~km}$ from the coast, and larger further offshore with regression slopes of $0.53( \pm 0.22)$ and $1.32( \pm 0.23)$, respectively (Fig. 13). This is consistent with the results of Plattner et al. (2005) who found a substantial spatial decoupling between new and export production in the California CS with a decoupling length-scale of $300 \mathrm{~km}$. In contrast, in the Canary CS the values of the export and new production are, on average, very similar over the first $300 \mathrm{~km}$ from the coast (regression slope of $1.04( \pm 0.38)$ ), whereas in the $300 \mathrm{~km}-500 \mathrm{~km}$ offshore area the relationship between the new production and the export production deviate from a 1:1 relationship as is the case in the California CS with nearly identical regression slopes (regression slope of $1.33( \pm 0.25))$. We interpret the relatively small differences between export and new production in the nearshore areas of the Canary CS as an indicator of a much weaker decoupling between new and export production in this system in comparison to the California CS.

\subsection{Comparison with previous work}

The larger nutrient use efficiency in the Atlantic EBUS relative to the Pacific EBUS is consistent with several previous observational studies. For instance, Minas et al. (1986) found that the nutrient utilization is much larger in the Canary CS around $21^{\circ} \mathrm{N}$ than in the Peru upwelling system at $15^{\circ} \mathrm{S}$. In a global study of the 4 major EBUS, Carr and Kearns (2003) revealed that the Atlantic EBUS support twice the biomass of the Pacific EBUS for a given nutrient concentration. In a more recent observation-based comparative study of biological production in coastal upwelling systems, Lachkar and Gruber (2011) show that for a given upwelling intensity, biological NPP in the Atlantic EBUS is on average double that in the Pacific EBUS. To explain these differences, various hypotheses have been proposed in the literature involving differences in grazing pressure, iron-limitation, or physical forcing. Minas et al. (1986) for example proposed that the less efficient nutrient utilization in the Peru upwelling system relative to the Canary system might be due to the higher grazing pressure in the first. Other studies hypothesized this might result from the differences in iron availability between the Atlantic and Pacific oceans (Fung et al., 2000; Carr and Kearns, 2003; Chavez and Messié, 2009). Various estimates of atmospheric dust deposition show indeed that the Atlantic EBUS and particularly the Canary CS receive larger flux of dust from Saharan regions than do the California and Humboldt upwelling regions (Jickells et al., 2005; Mackas et al., 2006). Moreover, the stronger iron limitation in the Pacific EBUS may be further exacerbated due to their relatively narrow continental shelves limiting the benthic availability of iron (Chase et al., 2007). More recently, Lachkar and Gruber (2011) associated the lower nutrient utilization efficiency in the Pacific EBUS to stronger inhibiting conditions essentially induced by narrower continental shelves and higher mesoscale activity relative to the Atlantic Ocean. The inhibiting role of mesoscale processes has been interpreted by Gruber et al. (2011) as a consequence of their causing a net offshore transport of nutrients, thereby depleting the nearshore nutrient reservoir in the thermocline. In addition to this eddy-suppressing mechanism we show in the present study that mesoscale processes further reduce the efficiency with which these nutrients are being utilized within the euphotic zone. These two mechanisms tend to reinforce each other, making NPP in the California CS much lower than expectations based on the upwelling strength and deep North Pacific nutrient concentrations. 
Obviously, none of these mechanisms is exclusive of another. Yet, the fact that we successfully reproduced the contrasts in NPP between the Canary and California CS using a simple NPZD-type ecosystem model indicates that physical processes likely dominate in explaining the differences in NPP and biomass between these systems. This needs, however, to be confirmed through a series of simulations performed with models that contain more details in terms of biogeochemical controls (e.g. iron) and/or resolve the ecosystem with more phytoplankton functional groups.

\section{Summary and conclusions}

We investigated the major drivers of the biological production in EBUS using a comparative modeling study of two of the four major EBUS, namely the California CS and the Canary CS. Our aim has been to identify and compare the production limitations in these two systems, and to explore the mechanisms that control the sensitivity of biological production to upwelling-favorable wind forcing.

Directly comparable eddy-resolving simulations of the California CS and the Canary CS show that despite nutrient concentrations on average being about $20 \%$ larger in the first, NPP is $50 \%$ larger in the second, indicating a considerably larger nutrient use efficiency in the Canary CS. By analyzing phytoplankton growth in nutrient-replete conditions, we found that this more efficient use of nutrients in the Canary CS is essentially due to more favorable light and temperature conditions, resulting in an overall $12 \%$ higher growth rate in the Canary CS in comparison with the California CS. Yet, comparable growth rates in the Canary CS and the California CS are associated with substantially larger productivities in the former. This is due to large contrasts in the water residence times in the nearshore between the two systems.

We found that the newly upwelled water stays on average more than $50 \%$ longer in the nearshore area of the Canary CS relative to the California CS. This enhances the buildup of biomass in the coastal zone of the Canary CS and leads to higher production, larger local recycling of nutrients, and much weaker decoupling between new and export production. Additional simulations demonstrate that the wider shelf and the lower level of mesoscale activity in the Canary CS relative to the California CS both likely contribute to the longer water residence time in the former.

Overall, our results show that factors affecting timescales of biological growth such as the light and temperature and those related to the dynamics of the cross-shore circulation in coastal upwelling systems such as the shelf topography and the level of eddy activity exert a strong control on nutrient use efficiency, and thus, on the sensitivity of biological production to the intensity of upwelling. Therefore, this study suggests that the biological response to climate change induced perturbations such as upwelling favorable wind intensification (e.g. Bakun, 1990) or increased stratification (e.g. Rykaczewski and Dunne, 2010) might lead to contrasting biological responses in the California CS and the Canary $\mathrm{CS}$, with major implications for the biogeochemical cycles and fisheries in these two ecosystems.

Acknowledgements. Support for this research has come from the Swiss Federal Institute of Technology Zurich (ETH Zurich). Computations were performed at the central computing cluster of ETH Zurich, Brutus. We are indebted to J. McWilliams and his research group for the development, maintenance, and sharing of the physical component of ROMS. We thank H. Frenzel and D. Loher for their code support. We are grateful to B. Blanke and N. Grima for making their ARIANE code available. We also thank the various providers of the satellite data, in particular the SeaWiFS Project (Code 970.2) sponsored by NASA's Mission to Planet Earth program, as well as the AVHRR data products sponsored by the NOAA/NASA Polar Pathfinder program.

Edited by: G. Herndl

\section{References}

Allen, J.: Upwelling and Coastal Jets in a Continuously Stratified Ocean, J. Phys. Oceanogr., 3, 245-257, 1973.

Arístegui, J., Barton, E. D., Tett, P., Montero, M. F., GarcaMuoz, M., Basterretxea, G., Cussatlegras, A., Ojeda, A., and de Armas, D.: Variability in plankton community structure, metabolism, and vertical carbon fluxes along an upwelling filament (Cape Juby, NW Africa), Progr. Oceanogr., 62, 95-113, doi:10.1016/j.pocean.2004.07.004, 2004.

Arístegui, J., Barton, E. D., Alvarez-Salgado, X. A., Santos, M., Figuerias, F.G., Kifani, S., Hernandez-Leon, S., Mason, E., Machu, E., and Demarcq, H.: Sub-regional ecosystem variability in the Canary Current upwelling, Progr. Oceanogr., 83, 33-48, doi:10.1016/j.pocean.2009.07.031, 2009.

Austin, J. A. and Lentz, S. J.: The Inner Shelf Response to WindDriven Upwelling and Downwelling, J. Phys. Oceanogr., 32, 2171-2193, 2002.

Bakun, A.: Global Climate Change and Intensification of Coastal Ocean Upwelling, Science, 247, 198-201, doi:10.1126/science.247.4939.198, 1990.

Barnier, B., Siefried, L., and Marchesiello, P.: Thermal forcing for a global ocean circulation model using a three-year climatology of ECMWF analyses, J. Mar. Syst., 6, 363-380, 1995.

Beckmann, A. and Haidvogel, D. B.: Numerical simulation of flow around a tall isolated seamount. Part I: Problem formulation and model accuracy, J. Phys. Oceanogr., 23, 1736-1753., 1993.

Berger, W. H., Smetacek, V. S. and Wefer, G.: Ocean productivity and paleoproductivity-An overview, in Productivity of the Ocean: Present and Past, edited by: Berger, W. H., Smetacek, V. S., and Wefer, G., 1-35, John Wiley, Hoboken, N. J., 1989.

Blanke, B. and Raynaud, S.: Kinematics of the Pacific Equatorial Undercurrent: an Eulerian and Lagrangian approach from GCM results, J. Phys. Oceanogr., 27, 1038-1053, 1997.

Brink, K.: The near-surface dynamics of coastal upwelling, Prog. Oceanogr., 12, 223-257, doi:10.1016/0079-6611(83)90009-5, 1983. 
Carr, M.: Estimation of potential productivity in Eastern Boundary Currents using remote sensing, Deep Sea Res. Pt. II, 49, 59-80, doi:10.1016/S0967-0645(01)00094-7, 2001.

Carr, M. and Kearns, E. J.: Production regimes in four Eastern Boundary Current systems, Deep Sea Res. Pt. II, 50, 3199-3221, doi:10.1016/j.dsr2.2003.07.015, 2003.

Capet, X. J., Marchesiello, P., and McWilliams, J. C.: Upwelling response to coastal wind profiles, Geophys. Res. Lett., 31, L13311, doi:10.1029/2004GL020123, 2004.

Chase, Z., Strutton, P. G., and Hales, B.: Iron links river runoff and shelf width to phytoplankton biomass along the U.S. West Coast, 2007.

Chassignet, E. P. and Verron, J.: Ocean Weather Forecasting: An Integrated View of Oceanography, Springer, Dordrecht, The Netherlands, 2006.

Chavez, F. P. and Toggweiler, J. R.: Physical estimates of global new production: The upwelling contribution, in: Upwelling in the Ocean: Modern Processes and Ancient Records, edited by: Summerhayes, C. P., Emeis, K.-C., Angel, M. V., Smith, R. L., and Zeitzschel, B., 313-320, ISBN:978-0471960416, John Wiley, New York, 1995.

Chavez, F. P. and Messié, M.: A comparison of Eastern Boundary Upwelling Ecosystems, Prog. Oceanogr., 83, 80-96, doi:10.1016/j.pocean.2009.07.032, 2009.

Chelton, D. B., deSzoeke, R. A., Schlax, M. G., Naggar, K. E., and Siwertz, N.: Geographical variability of the first-baroclinic Rossby radius of deformation, J. Phys. Oceanogr., 28, 433-460, 1998.

da Silva, A. M., Young, C. C., and Levitus, S.: Atlas of surface marine data 1994. Volume 1: algorithms and procedures, Technical Report NOAA Atlas NESDIS 6, National Oceanic and Atmospheric Administration, Washington, DC, 1994.

de Boyer Montégut, C., Madec, G., Fischer, A. S., Lazar, A., and Iudicone, D.: Mixed layer depth over the global ocean: an examination of profile data and a profile-based climatology, J. Geophys. Res., 109, C12003, doi:10.1029/2004JC002378, 2004.

Demarcq, H.: Trends in primary production, sea surface temperature and wind in upwelling systems (1998-2007), Prog. Oceanogr., 83, 376-385, doi:10.1016/j.pocean.2009.07.022, 2009.

Falkowski, P. G. and Raven., J.: Aquatic Photosynthesis, Blackwell, Oxford 375 pp, 1997.

FAO: The State of World Fisheries and Aquaculture 2008, Food \& Agriculture Org, Pap/Cdr edn., 2009.

Eppley, R. W.: Temperature and phytoplankton growth in the sea, Fish. Bull., 70, 1063-1085, 1972.

Eppley, R. W. and Peterson, B. J.: Particulate organic matter flux and planktonic new production in the deep ocean, Nature, 282, 677-680, 1979.

Friedrichs, M. A. M. and Hofmann, E. E.: Physical control of biological processes in the central equatorial Pacific Ocean, DeepSea Res. Pt. I, 48, 1023-1069, 2001.

Friedrichs, M. A. M., Hood, R. H., and Wiggert, J. D.: Ecosystem model complexity versus physical forcing: Quantification of their relative impact with assimilated Arabian Sea data, DeepSea Res. Pt. II, 53, 576-600, 2006.

Friedrichs, M. A. M., Dusenberry, J. A., Anderson, L. A., Armstrong, R. A., Chai, F., Christian, J. R., Doney, S. C., Dunne, J., Fujii, M., Hood, R., Mcgillicuddy, D. J., Moore, J. K., Schar- tau, M., Spitz, Y. H., and Wiggert, J. D.: Assessment of skill and portability in regional marine biogeochemical models: Role of multiple planktonic groups, J. Geophys. Res.-Oceans, 112, C08001, 22 pp., doi:10.1029/2006JC003852, 2007.

Fung, I., Meyn, S. K., Tegen, I., Doney, S., John, J., and Bishop, J.: Iron supply and demand in the upper ocean, Global Biogeochem. Сy., 14, 281-295, 2000.

Gruber, N., Frenzel, H., Doney, S. C., Marchesiello, P., McWilliams, J. C., Moisan, J. R.., Oram, J., Plattner, G.-K., and Stolzenbach, K. D..: Eddy-resolving simulation of plankton ecosystem dynamics in the California Current System, Deep-Sea Res. Pt. I, 53, 1483-1516, doi:10.1016/j.dsr.2006.06.005. 2006

Gruber, N., Lachkar, Z., Frenzel, H., Marchesiello, P., Munnich, M., McWilliams, J. C., Nagai, T., and Plattner, G.: Mesoscale eddyinduced reduction of biological production in coastal upwelling systems, Nat. Geosci., doi:10.1038/ngeo1273, 2011.

Hood, R. R., Kohler, K. E., McCreary, J. P., and Smith, S. L.:A fourdimensional validation of a coupled physical-biological model of the Arabian Sea, Deep-Sea Res. Pt. II, 50, 2917-2945, 2003.

Hyde, K., O'Reilly, J., and Oviatt, C.: Validation of SeaWiFS chlorophyll- $a$ in Massachusetts Bay, Cont. Shelf Res., 27, 16771691, 2007.

Jickells, T. D, An, Z. S., Andersen, K. K., Baker, A. R., Bergametti, G., Brooks, N., Cao, J. J, Boyd, P. W., Duce, R. A., Hunter, K. A., Kawahata, K., Kubilay, N., laRoche, J., Liss, P. S., Mahowald, N., Prospero, J. M., Ridgwell, A. J., Tegen, I., and Torres., R.: Global Iron Connections Between Desert Dust, Ocean Biogeochemistry, and Climate, Science, 308, 5718, 6771, doi:10.1126/science.1105959, 2005.

Kahru, M., Kudela, R., Manzano-Sarabia, M., and Mitchell, B. G.: Trends in primary production in the California Current detected with satellite data, J. Geophys. Res., 114, C02004, doi:10.1029/2008JC004979, 2009.

Lachkar, Z. and Gruber, N.: A comparative study of biological production in eastern boundary upwelling systems using an artificial neural network, Biogeosciences Discuss., 8, 9901-9941, doi:10.5194/bgd-8-9901-2011, 2011.

Large, W. G., McWilliams, J. C., and Doney, S. C.: Oceanic vertical mixing: A review and a model with a nonlocal boundary layer parameterization, Reviews of Geophys. Res., 32, 363-403, 1994.

Mackas, D. L., Strub, P. T., Thomas, A., and Montecino, V.: Eastern ocean boundaries, vol. 2 of The Seal, edited by: Robinson, A. R. and Brink, K. H., 21-59, Harvard University Press, 2006.

Marchesiello, P., McWilliams, J. C., and Shchepetkin, A. F.: Open boundary conditions for long-term integration of regional oceanic models, Ocean Modell., 3, 1-20, 2001.

Marchesiello, P., McWilliams, J. C., and Shchepetkin, A. F.: Equilibrium structure and dynamics of the California Current system, J. Phys. Oceanogr., 33, 753-783, 2003.

Marchesiello, P. and Estrade, P.: Eddy activity and mixing in upwelling systems: a comparative study of Northwest Africa and California regions, Int. J. Earth Sci., 98, 299-308, doi:10.1007/s00531-007-0235-6, 2009.

McGregor, H. V., Dima, M., Fischer, H. W., and Mulitza, S.: Rapid 20th-Century Increase in Coastal Upwelling off Northwest Africa, Science, 315, 637-639, doi:10.1126/science.1134839, 2007.

Mendelssohn, R. and Schwing, F. B.: Common and uncommon trends in SST and wind stress in the California and Peru-Chile 
current systems, Prog. Oceanogr., 53, 141-162, ISSN:00796611, doi:10.1016/S0079-6611(02)00028-9, 2002.

Minas, H. J., Minas, M., and Packard, T. T.: Productivity in upwelling systems deduced from hydrographic and chemical fields, Limnol. Oceanogr., 31, 1182-1206, 1986.

Muller-Karger, F. E., Varela, R., Thunell, R., Luerssen, R., Hu, C., and Walsh, J. J.: The importance of continental margins in the global carbon cycle, Geophys. Res. Lett., 32, L01602, doi:10.1029/2008JC004979, 2005.

Pauly, D. and Christensen, V.: Primary production required to sustain global fisheries, Nature, 374, 255-257, doi:10.1038/374255a0, 1995.

Plattner, G. -K., Gruber, N., Frenzel, H., and McWilliams, J. C.: Decoupling marine export production from new production, Geophys. Res. Lett., 32, L11612, doi:10.1029/2005GL022660, 2005.

Risien, C. M. and Chelton, D. B.: A global climatology of surface wind and wind stress fields from eight years of QuikSCAT scatterometer data, J. Phys. Oceanogr., 38, 2379-2413, 2008.

Rossi, V., C. López, C., Sudre, J., Hernández-Garca, E., and Garçon, V.: Comparative study of mixing and biological activity of the Benguela and Canary upwelling systems, Geophys. Res. Lett., 35, L11602, doi:10.1029/2008GL033610, 2008.

Rykaczewski, R. R. and Dunne, J. P.: Enhanced nutrient supply to the California Current Ecosystem with global warming and increased stratification in an earth system model, Geophys. Res. Lett., 37, L21606, doi:10.1029/2010GL045019, 2010.

Schollaert, S. E., Yoder, J. A., O'Reilly, J. E., Westphal, D. L.: Influence of dust and sulfate aerosols on ocean color spectra and chlorophyll $a$ concentrations derived from SeaWiFS off the US east coast, J. Geophys. Res., 108, 3191, 1-13, doi:10.1029/2000JC000555, 2003.
Shannon, L., Crawford, R., Pollock, D., Hutchings, L., Boyd, A., Taunton-Clark, J., Badenhorst, A., Melville-Smith, R., Augustyn, C., Cochrane, K., Hampton, I., Nelson, G., Japp, D., and Tarr, R.: The 1980s a decade of change in the Benguela ecosystem, South African Journal of Marine Science, 12, 271 296, 1992.

Shchepetkin, A. F. and McWilliams, J. C.: Quasi-monotone advection schemes based on explicit locally adaptive dissipation, Mon. Weather Rev., 126, 1541-1580, 1998.

Shchepetkin, A. F. and McWilliams, J. C.: The regional oceanic modeling system (ROMS): A split-explicit, free-surface, topography- following-coordinate oceanic model, Ocean Modell. IX, 347-404, Hooke Inst. Oxford Univ., Oxford, U. K., 2005.

Smith, W. H. F. and Sandwell, D. T.: Global seafloor topography from satellite altimetry and ship depth soundings, Science, 277, 1957-1962, 1997.

Taylor, K. E.: Summarizing multiple aspects of model performance in a single diagram, J. Geophys. Res., 106, 7183-7192, 2001.

Tilstone, G., Smyth, T., Poulton, A., and Hutson, R.: Measured and remotely sensed estimates of primary production in the Atlantic Ocean from 1998 to 2005, Deep Sea Res. Pt. II, 56, 918-930, doi:10.1016/j.dsr2.2008.10.034, 2009.

Thomas, A. C., Carr, M.-E., and Strub, P. T.: Chlorophyll variability in Eastern Boundary Currents, Geophys. Res. Lett., 28, 34213424, 2001.

Wroblewski, J. S.: A model of phytoplankton plume formation during variable Oregon upwelling, J. Mar. Res., 35, 357-394, 1977. 